\title{
Scenery of Staphylococcus implant infections in orthopedics
}

Lucio Montanaro',2, Pietro Speziale ${ }^{3}$, Davide Campoccia', Stefano Ravaioli ${ }^{1,2}$, llaria Cangini ${ }^{1,2}$, Giampiero Pietrocola ${ }^{3}$, Sandro Giannini ${ }^{4}$ \& Carla Renata Arciola ${ }^{\dagger 1,2}$

'Research Unit on Implant Infections, Rizzoli Orthopaedic Institute, Via di Barbiano 1/10, 40136 Bologna, Italy 2Department of Experimental Pathology of the University of Bologna, Via S. Giacomo 14, 40126 Bologna, Italy ${ }^{3}$ Department of Biochemistry of the University of Pavia, Viale Taramelli 3/b, 27100 Pavia, Italy

${ }^{4}$ Clinical Orthopaedic \& Traumatology Unit II, Rizzoli Orthopaedic Institute, via G.C. Pupilli 1.

40136 Bologna, Italy

†Author for correspondence: Tel. : +39051 6366599 m Fax: +39 0516366599 m carlarenata.arciola@ior.it

Infection is still the major complication of orthopedic implants and projections based on the actual trend indicate that total hip and knee arthroplasties and their consequent infection burden are destined to greatly increase. Staphylococcus aureus and Staphylococcus epidermidis are the leading etiologic agents of orthopedic implant infection. Here we report on epidemiology of implant-related Staphylococcus infections in orthopedics, also referring to our experience, and focus on the crucial role of bacterial adhesins and on their ability to direct the pathogenesis process. Bacteria initiate implant infection by adhering to biomaterials. In the early steps of infection, adhesins mediate the specific interaction between microbial cells and the extracellular matrix proteins filming biomaterial surface. Then adhesin-mediated anchorage allows bacteria to cling to the biomaterial surface and to produce a biofilm that favors their ability to resist antibiotics. With the aim to prevent implant-related infections, anti-infective and infection-resistant biomaterials are being developed. The research for novel therapeutic strategies is incited by the emergence of antibiotic-resistant bacteria. Vaccines against the adhesins or antisense molecules against virulence genes can open a future in combating implant infections.

The scenery of orthopedic implants: projections of the number of primary \& revision arthroplasties

In orthopedics, implant procedures to restore the function of affected joints, fractured bone segments and impaired limbs are progressively boosting. The expansion of joint replacement surgery and the need to follow the outcome and costs of the arthroplasties booming have promoted the foundation of many registries at the regional, national and international level. The registries provide important information on the long-term effectiveness and quality of implants. The structure, functioning and content of many arthroplasty registers are examined and evaluated in a recent comprehensive review [1].

The number of primary and revision arthroplasties is increasing constantly worldwide [2]. Projections of the number of primary and revision total hip and knee arthroplasties that will be performed in the USA until 2030 have been formulated and the percent increases in respect to 2005 have been estimated [2]. By 2030, the demand for primary total hip arthroplasties is estimated to reach 572,000 , with an increase of $174 \%$. The demand for primary total knee arthroplasties will reach 3.48 million, an increase of $673 \%$ (Figure $1 \&$ Box 1).
The National Joint Registry (NJR) for England and Wales, 7th Annual Report, 2010, has now collected more than 905,000 procedures registered, making the NJR by far the largest registry of its kind in the world. In 2009, there were 72,432 hip replacement procedures recorded on the NJR. Of these, 65,229 were primary procedures and 7203 were revision surgeries, representing a revision 'burden' of $10 \%$. Indications for revision were aseptic loosening (56\%) and infection (3\%).

The number of knee replacement procedures recorded on the NJR during 2009 was 77,545. There were 4565 revision procedures, representing $5.9 \%$ of the total number of knee replacement procedures in 2009 (Figure 2).

\section{Infection burden for hip \& knee arthroplasties}

For a long time experimental evidence has been gathered that the presence of a foreign body reduces the minimal inoculum of $S$. aureus that is required to cause infection by a factor of more than 100,000 [3,4]. Experimental observations with animal models show that in the presence of a foreign body, infection may occur despite the use of perioperative antimicrobial prophylaxis, since fewer than $100 \mathrm{CFU}$ of microorganisms

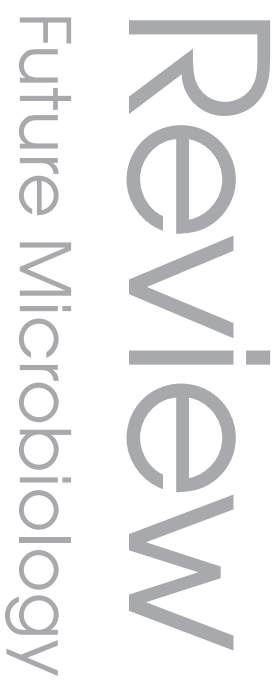

\section{Keywords}

- adhesins m antibiotic-loaded biomaterials $=$ biofilm $=$ DNA vaccines - implant infections - infection-resistant materials - MSCRAMMs m orthopedic implants = peptide-nucleicacids $\approx$ Staphylococcus aureus $=$ Staphylococcus epidermidis $m$ vaccines

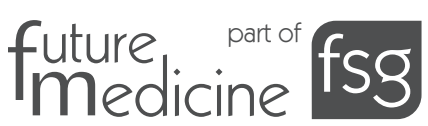




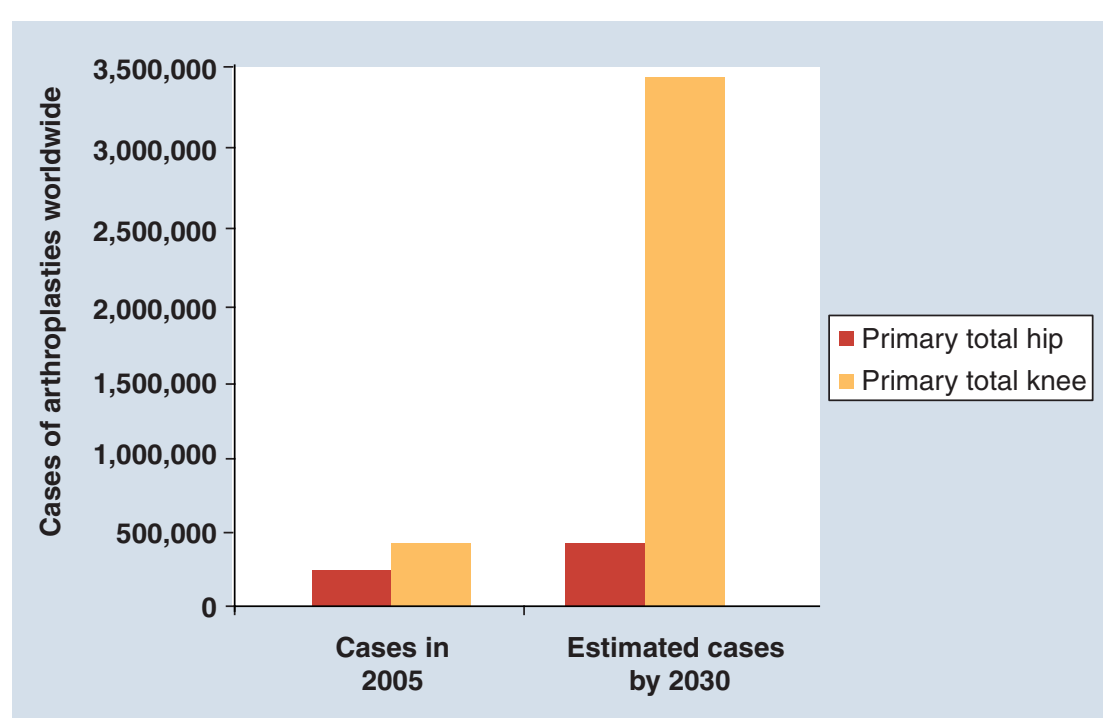

Figure 1. Projections of worldwide increase of arthroplasties from 2005 to 2030. reconstruction, resulting in significant morbidity to the patient and increased hospital costs. To quote the words of Sculco written back in 1993 "Infection in total joint replacement is a devastating and life-threatening complication for the patient. It can also be an economic disaster for hospitals that treat large numbers of these patients" [9]. Since then, things may have changed, but implant infection still remains a health and economic problem. The current and historical incidence of periprosthetic infection associated with hip and knee arthroplasty in the USA, as well as the corresponding hospitalization charges and the lengths of stay have been calculated using the Nationwide Inpatient Sample. According to Kurtz et al. [2], to Katz et al. [10] and to Mahomed et al. [11] the short-term risk of periprosthetic infection ranges between 0.2 and $0.4 \%$ for primary total hip arthroplasty and total knee arthroplasty, respectively.

Applying these estimates to the expected increase of arthroplasties in the USA and in the UK, the infections for hip and knee arthroplasties may reach worrying numbers according to Jämsen et al. [12].

Currently the infection rates are approximately $1 \%$ in primary knee replacements and $0.3-0.6 \%$ in hip replacements [13-15]. However, even prospective surveillance programs may underestimate the infection rates; thus, the true incidence is probably higher $[16,17]$.

Currently, periprosthetic infection is most frequently diagnosed by the isolation of one or more microorganisms from periprosthetic tissue or fluid with the use of conventional microbiologic culture techniques, and the results of microbiologic culture are usually considered the standard with which other diagnostic tests are compared.

The current classification of American Association of Orthopedic Surgeons divides prosthetic infections into the following four types [18]:

- Type 1 (positive intraoperative culture): two intraoperative cultures turning out positive;

\section{Box 1. Future demand for arthroplasties.}

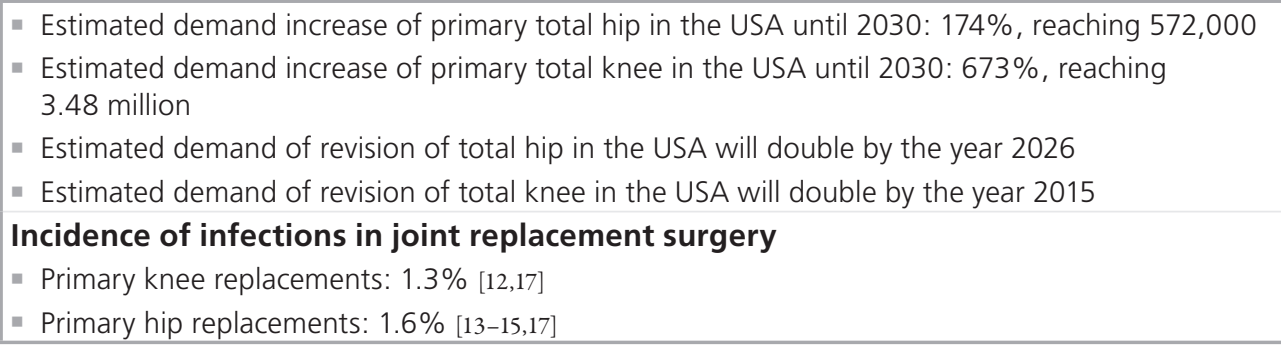


- Type 2 (early postoperative infection): infection occurring within the first month after surgery;

- Type 3 (acute hematogenous infection): hematogenous seeding of site of previously well-functioning prosthesis;

- Type 4 (late chronic infection): chronic indolent clinical course; infection present for more than 1 month.

In a slightly different classification by Zimmerli et al. [19], infections associated with prosthetic joints are divided into the following categories:

- Early (those that develop less than 3 months after surgery);

- Delayed (3-24 months after surgery), or;

- Late (more than 24 months after surgery).

The most common bacteria isolated from infected joints are coagulase-positive or -negative Staphylococcus [20,21]. The infecting organisms are either introduced during implantation of a prosthesis or derived from a temporary bacteremia. They then adhere to biomaterials and grow to form a biofilm. The mode of growth in biofilm offers enhanced protection against natural host defenses and antibiotic therapies [22].

\section{Epidemiology of implant-related} Staphylococcus infections in orthopedics in our experience

In the past we have conducted a large study on a collection of 1027 isolates, obtained in the period between 2000 and 2003 from 699 orthopedic patients bearing infections [21]. The results compared the etiology of infections associated with medical devices (MDs) to those developed in the absence of implant materials (no MDs). MDs included infections associated to knee and hip prostheses, external and internal fractured bone fixation systems, materials for tendon and ligament reconstructions and other orthopedic implant materials. Staphylococcal species were found to be the most prevalent etiological agents of orthopedic infections, representing $75.3 \%$ of all strains, $78.1 \%$ of the isolates obtained from MDs and just $68.3 \%$ of those from the no MD group. Among the species belonging to the Staphylococcus genus, S. aureus generally exhibited the highest prevalence $(35.5 \%$ overall prevalence, $33.8 \%$ in MDs and $40.3 \%$ in the no MD group), closely approached by Staphylococcus epidermidis only in the presence of a foreign body. No single bacterial species, except for $S$. aureus and $S$. epidermidis, exceeded a frequency of $7 \%$, giving emphasis to the critical importance of these two species in the epidemiology of orthopedic infections [21].

Recently we have analyzed an analog collection of isolates from 242 orthopedic patients referring to the period between 2007 and 2011. The results derived from the new study matched rather well with, and confirmed those of, the old epidemiological investigation. Again the prevalence of staphylococci in the entire collection was approximately $75 \%$, slightly higher in the case of MDs (82.3\%) and lower for no MDs (65.4\%). Table 1 reports in detail each etiological agent identified and the respective frequency based on the category of infection. S. aureus again represents approximately $35 \%$ of all the isolates. The coagulase-negative species are singularly reported in order to show the variety of minor staphylococcal species isolated from

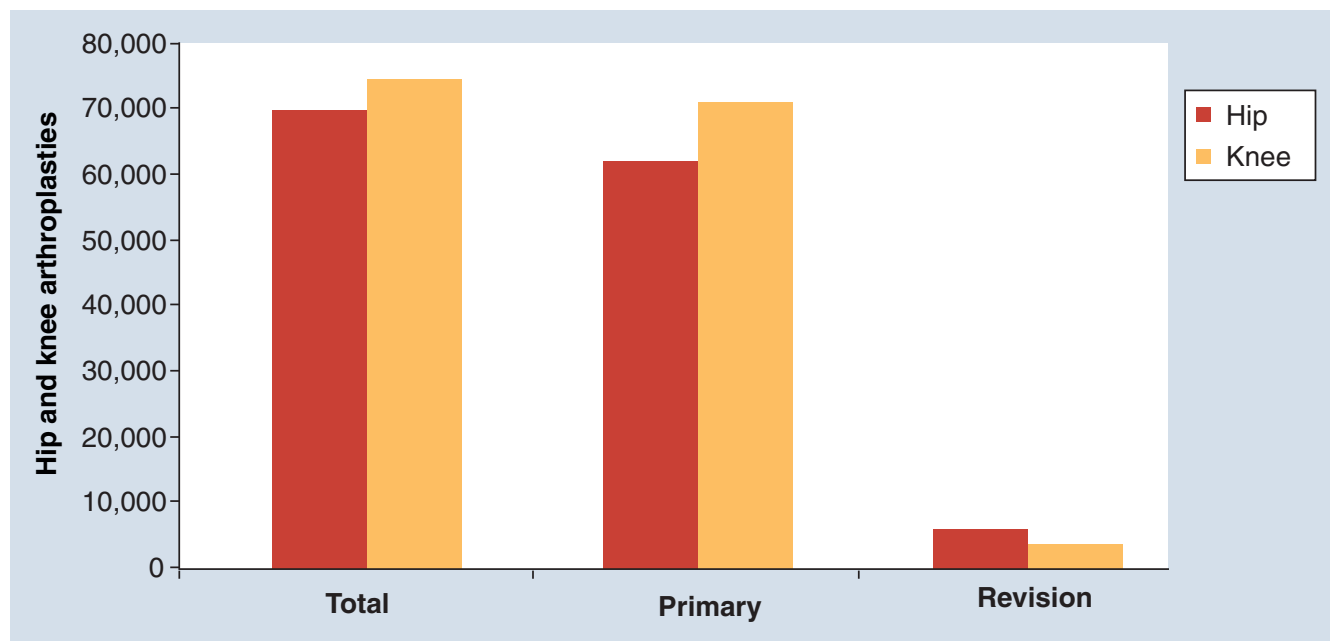

Figure 2. Hip and knee arthroplasties recorded by the National Joint Registry for England and Wales (cases of 2009). 
Table 1. Etiology of orthopedic infections (strains sampled in the period 2007-2011).

\begin{tabular}{|c|c|c|c|c|c|c|}
\hline \multirow[t]{2}{*}{ Microorganism } & \multicolumn{2}{|c|}{ All } & \multicolumn{2}{|c|}{ MDs } & \multicolumn{2}{|c|}{ No MDs } \\
\hline & $n$ & $\%$ & $n$ & $\%$ & $n$ & $\%$ \\
\hline Staphylococcus aureus & 95 & 35.1 & 52 & 31.7 & 43 & 40.2 \\
\hline Pseudomonas aeruginosa & 25 & 9.2 & 10 & 6.1 & 15 & 14.0 \\
\hline Enterococcus faecalis & 11 & 4.1 & 4 & 2.4 & 7 & 6.5 \\
\hline Staphylococcus haemolyticus & 9 & 3.3 & 3 & 1.8 & 6 & 5.6 \\
\hline Staphylococcus warneri & 8 & 3.0 & 8 & 4.9 & 0 & 0.0 \\
\hline Staphylococcus hominis & 5 & 1.8 & 4 & 2.4 & 1 & 0.9 \\
\hline Streptococcus agalactiae & 4 & 1.5 & 1 & 0.6 & 3 & 2.8 \\
\hline Proteus mirabilis & 4 & 1.5 & 2 & 1.2 & 2 & 1.9 \\
\hline Staphylococcus lugdunensis & 3 & 1.1 & 2 & 1.2 & 1 & 0.9 \\
\hline Enterococcus faecium & 2 & 0.7 & 1 & 0.6 & 1 & 0.9 \\
\hline Morganella morganii & 2 & 0.7 & 2 & 1.2 & 0 & 0.0 \\
\hline Staphylococcus cohnii & 1 & 0.4 & 1 & 0.6 & 0 & 0.0 \\
\hline Corynebacterium striatum & 1 & 0.4 & 0 & 0.0 & 1 & 0.9 \\
\hline Serratia spp. & 3 & 1.1 & $2^{+}$ & 1.2 & $1^{\ddagger}$ & 0.9 \\
\hline Total: & 271 & & 164 & & 107 & \\
\hline
\end{tabular}

orthopedic infections, representing new pathogens in implant infections [23]. We observed that the prevalence of $S$. epidermidis has increased from $31.5 \%$ in the old collection to $39.0 \%$ in the new collection $\left(\chi^{2}\right.$, p value $\left.=0.06\right)$, revealing that this coagulase-negative Staphylococcus is progressively prevailing on $S$. aureus. The only statistically significant difference emerging from the analysis of the first five most prevalent species concerned Pseudomonas aeruginosa, which increased among the no MDs group from the earlier observed $6.8 \%$ to the current $14.0 \%\left(\chi^{2}, \mathrm{p}\right.$ value $\left.=0.026\right)$, remaining actually unchanged in the case of MDs. Figure 3 shows that $S$. aureus has been found to be the main pathogen among infections in the no MD group and infections associated with internal and external fixation systems, while $S$. epidermidis was the most prevalent bacterial species among infections associated with knee and hip arthroprostheses.

Overall, our findings enlighten and further substantiate the abundant existing literature on the role of $S$. aureus in postsurgical orthopedic infections. At the same time they indicate that the role of $S$. aureus is different in the presence of MDs as a function of the category of implant and the conditions of application.
The complex role of microbial surface components recognizing adhesive matrix molecules adhesins in the early steps of infection

The particular versatility of $S$. aureus to originate distinct disease conditions with diverse clinical manifestations parallels the highly clonal and adaptable nature of this pathogen [24]. The identification of specific traits of virulence expressed by $S$. aureus strain types has directed most molecular epidemiology studies over the last decade. However, the particularly rich array of putative virulence factors encoded in the $S$. aureus genome has impeded many of the attempts to reveal a dominant virulence factor. The long-lasting controversy regarding the disputed role of the Panton-Valentine leukocidin in the development of skin infections caused by community-acquired methicillin-resistant $S$. aureus is an explicative example. After years of investigations and disputes, the real role played by Panton-Valentine leukocidin still remains unresolved [25].

In $S$. aureus, the so called 'virulon' consists of approximately 50 accessory genes [26], encoding for factors either secreted or expressed on the bacterial surface, all having a function in infection pathogenesis. These factors include toxins and a 
variety of other molecules mediating anti-inflammatory interactions, immune evasion, bacterial adhesion and colonization of host tissues, biofilm formation and host-cell invasion. In such context, adhesins represent an important group of virulence factors mediating surface adhesive interactions between microbial cells and host cells and extracellular matrix (ECM). They play a primary role, particularly in the early phases of infection, fulfilling tissue tropism, surface adhesion and colonization. However, specific adhesins have been found to act even as invasins and, furthermore, intervene in the process of bacterial internalization into host cells. Surface adhesion is a critical step in the pathogenesis of implantrelated infections and represents the initial start of a process opening the way to the colonization of biomaterial surfaces. For this reason, in the early 1990s the influence of adhesins on the adhesion and colonization of implant surfaces became a field of intense study [27-30]. Passive bacterial adsorption spontaneously occurs on material surfaces, but active stable anchorage of the microbial cells is established by adhesins (Figure 4), which bind to host proteins adsorbed on the implant surface following exposure to physiologic fluids.
S. aureus adhesins group includes the cell wall-anchored microbial surface components recognizing adhesive matrix molecules (MSCRAMMs) [31,32], as well as the recently described secretable expanded repertoire adhesive molecules (SERAMs), ionically rather than covalently associated to the bacterial cell wall [33]. MSCRAMMs, unlike SERAMs, are receptorial proteins anchored to the bacterial cell wall through a typical cell wall sorting signal Leu-Pro-X-Thr-Gly (LPXTG) motif. The $S$. aureus enzyme sortase A, located on the extracellular side of the membrane, cleaves the LPXTG motif, covalently anchoring the adhesin to the cell wall peptidoglycan [34]. Bound to the peptidoglycan and exposed on the bacterial surfaces, MSCRAMMs recognize specific ECM components. Their function is far from being totally clarified as the complex structure of MSCRAMMs often comprises multiple domains recognizing different ECM ligands or, alternatively, single domains with affinity for multiple alternative ligands. Through the interaction with ECM proteins, certain MSCRAMMs acting as invasins can facilitate the process of internalization into host cells. Other MSCRAMMs mediate bacterial cell accumulation, contributing to

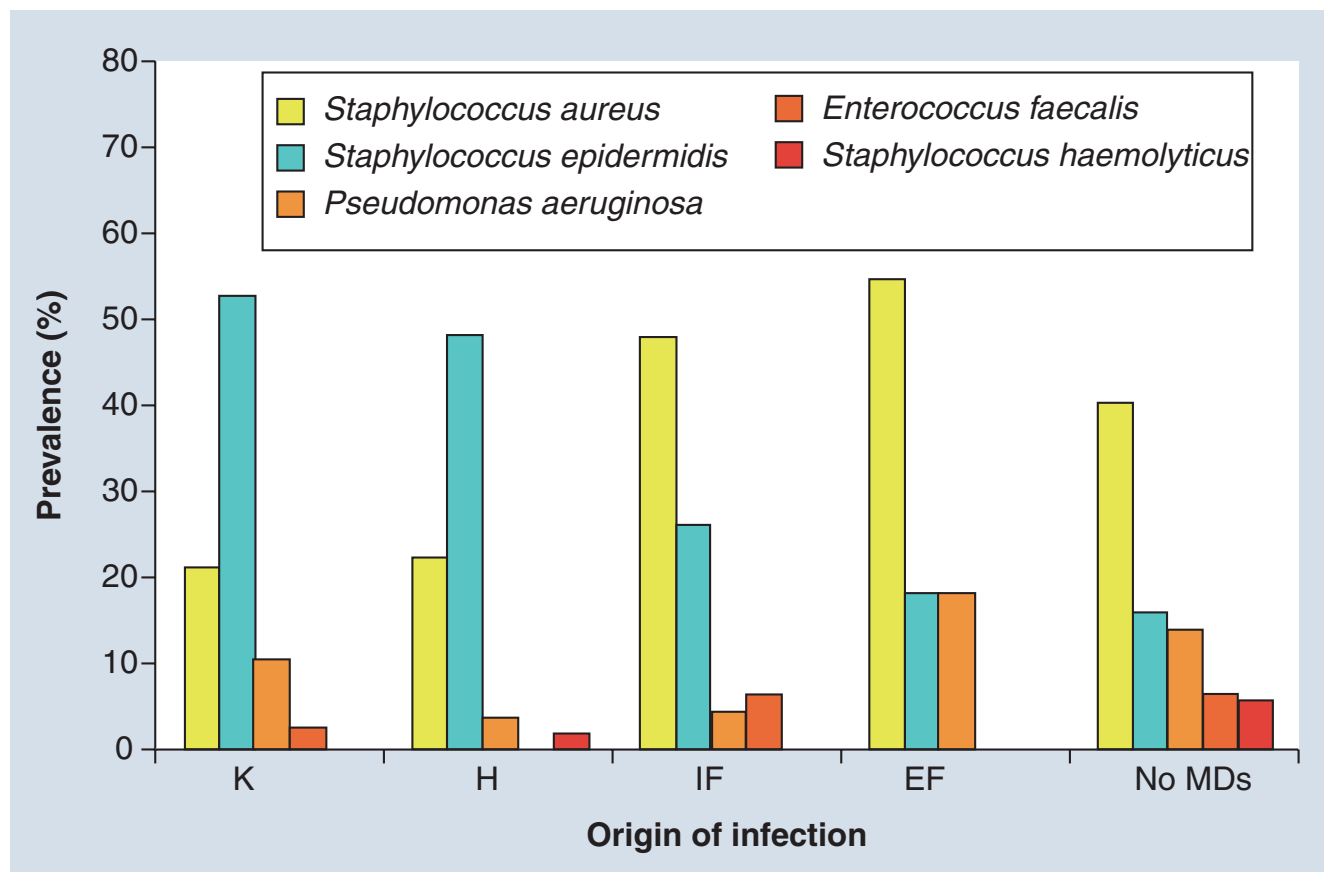

Figure 3. Prevalence of the five most frequent pathogens as a function of the origin of the orthopedic infection in a collection of 272 clinical isolates obtained from 242 patients in the period between 2007 and 2011. Confirming previous data, Staphylococcus aureus was found to be the main pathogen among infections not associated with medical devices and infections associated to IF and EF systems. Conversely, Staphylococcus epidermidis was the most prevalent bacterial species among infections associated to $\mathrm{K}$ and $\mathrm{H}$ arthroprostheses.

EF: External fixation; H: Hip; IF: Internal fixation; K: Knee; MD: Medical device. 


\section{Review Montanaro, Speziale, Campoccia et al.}

Bacterial attachment on protein-coated biomaterial surfaces by means of adhesins

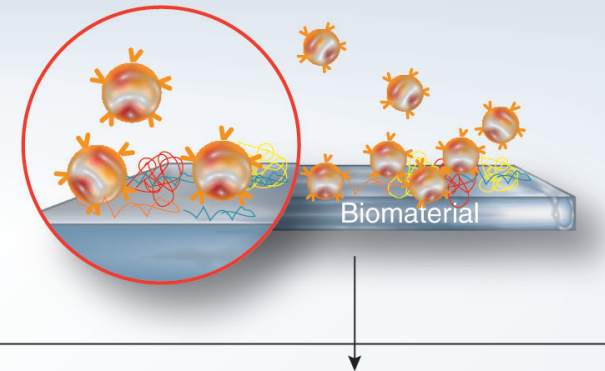

(ii) Biofilm formation through release of eDNA (iii) Biofilm formation through factors of proteic nature (i) Biofilm formation through exopolysaccharide production

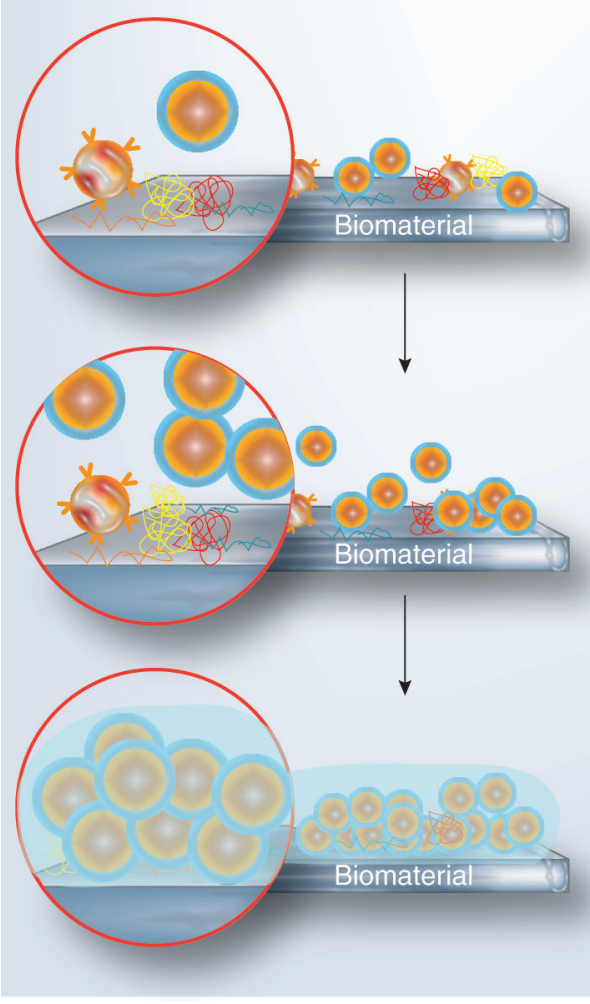

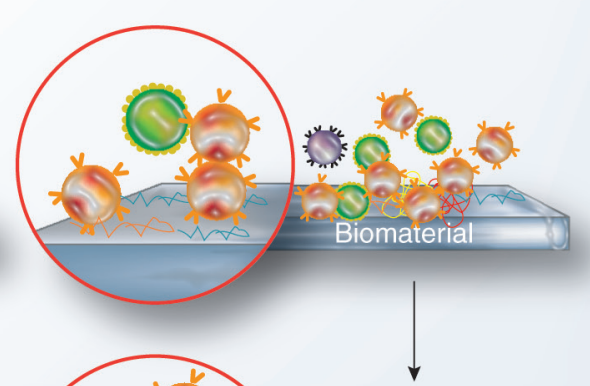

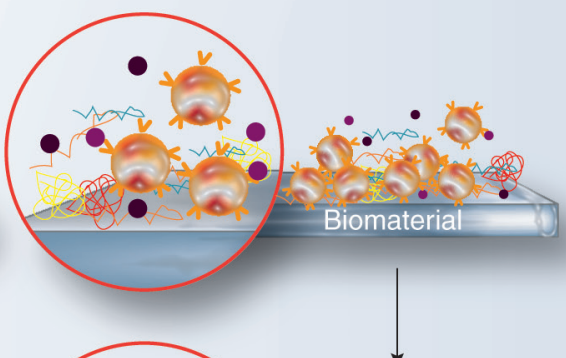

Figure 4. Bacterial attachment and fixation to biomaterial surfaces by a bacterial active process. Pathogens such as Staphylococcus aureus possess receptorial adhesins that bind to specific host proteins eventually adsorbed on the biomaterial surface. Initial bacterial adhesion can be followed by the formation of mature biofilms. At present, a number of alternative mechanisms are known that can enable biofilm formation: (i) the production of a glycocalix consisting of exopolysaccharidic-cementing substances enabling bacterial intercellular aggregation and subsequent encasement; (ii) the release of eDNA derived from mechanisms of altruistic suicide (or fratricidal microbial lysis in Enterococcus faecalis); (iii) finally, various protein factors are thought to be implicated in biofilm production, among them FnBPs, Aap, Bap and SpA.

biofilm formation by means of mechanisms alternative to the classical formation of that exopolysaccharide typical of most $S$. aureus strains and associated to the expression of an ica locus encoding for the polysaccharide intercellular adhesin (PIA). TAвle 2 reports a synoptic view of the multifaceted functions of most investigated $S$. aureus MSCRAMMs, enlightening at the same time the complexity of interactions actuated with host ECM components and the still large gap in terms of knowledge to be fulfilled. A number of SERAMs have been found to be associated with endovascular infections. Among them, coagulase, the extracellular fibrinogen-binding protein, the ECM-binding protein and the extracellular adhesive protein have been described to be the most prominent ones [33].

\section{Prevalence of adhesin genes in collections of $S$. aureus clinical isolates}

The role played by virulence factors can be investigated through a variety of experimental models and strategies, which include: in vitro and in vivo comparative models based on wild and mutant 


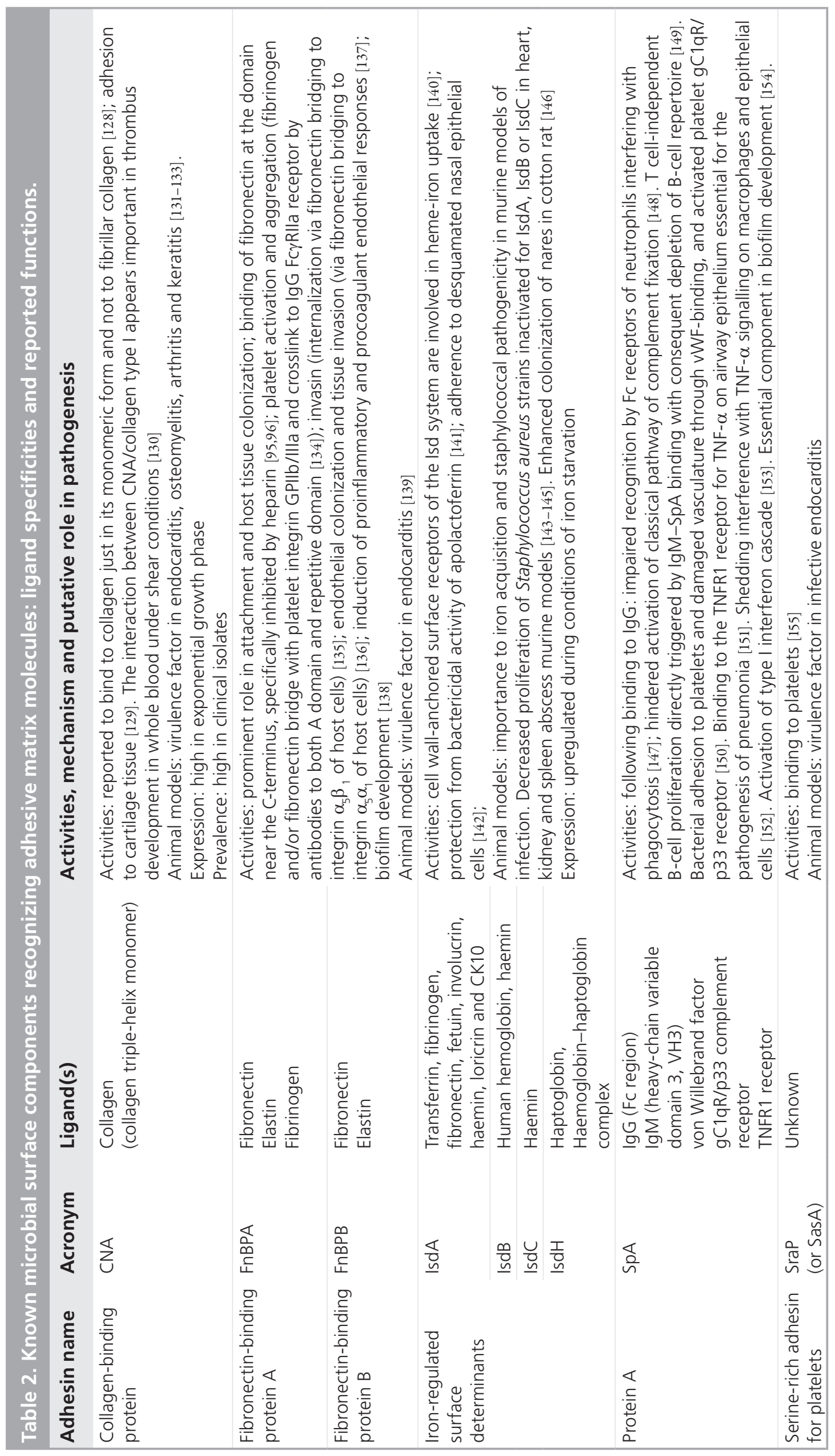




\section{Review Montanaro, Speziale, Campoccia et al.}

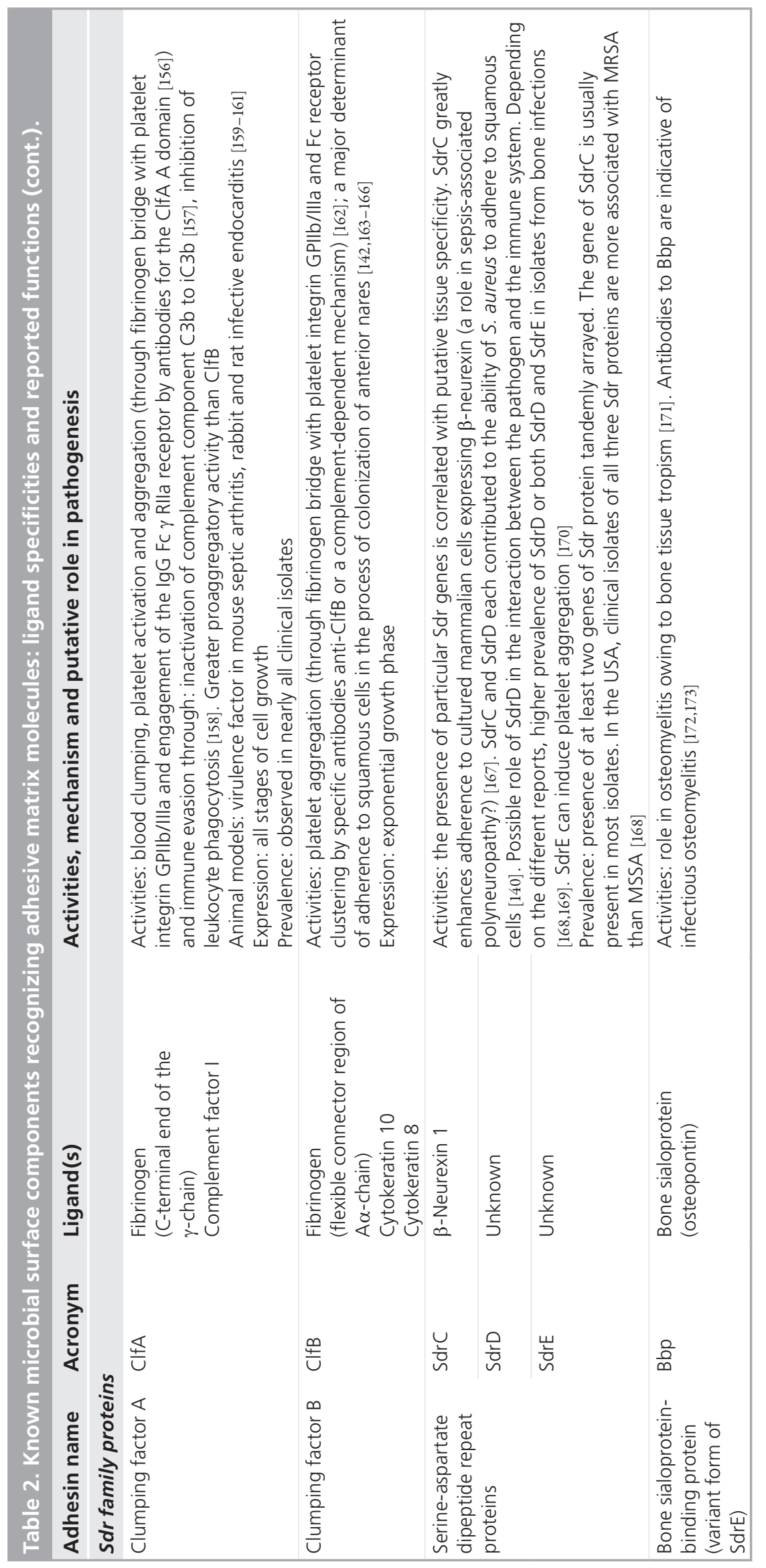


strains that are defective for a given virulence determinant; in vitro and in vivo models comparing groups of strains exhibiting or lacking such a determinant; transfer of the gene for a putative virulence trait in a nonpathogen species; molecular epidemiology studies assessing the distribution of the genes encoding for virulence factors in well-characterized collections of invasive, colonizing, contaminating or commensal strains; and molecular epidemiology studies surveying associations of well-defined virulence traits with newly confirmed emerging epidemic strain types. These different approaches offer a number of advantages and drawbacks. In vitro as well as in vivo animal models are often oversimplistic and unrepresentative of real clinical conditions involving human patients, even though experiments can be performed under appropriately selected and controlled conditions. Conversely, studies based on clinical isolates require longterm collection and storage of a vast number of isolates, their extensive molecular characterization, including strain subtyping and a full access to the data concerning the history of the patient and origin and development of the infection. Only recently, with complete sequencing of genomic DNA from different strain types, the selection of primers for PCR screening of target genes could be performed, keeping in consideration both stable and highly variable regions of adhesin genes. Thus, initial molecular epidemiology studies, blindly relying on subjectively chosen primers, often led to noncomparable results among different authors.

Our earliest studies, in line with the efforts made by other pioneers investigating the pathogenesis of implant-related infections, were aimed at elucidating the role and weight of selected MSCRAMMs and of biofilm formation, which were thought to be relevant to the virulence of staphylococcal strains in the presence of orthopedic prosthetic materials [35-39]. At the time, the plausible involvement of MSCRAMMs in the processes of tissue tropism via active bacterial adhesion to tissue-specific ECM components and on ECM proteins-coated surfaces was strongly suggestive of a primary role of these factors in determining the colonization and subsequent infection of implants. Nevertheless, despite all these mounted expectations to identify a single adhesin or virulence factor capable of discriminating saprophytic contaminants from invasive pathogenic strains, the investigations inexorably ended showing at most a slightly increased prevalence of certain virulence traits among clinical isolates and never a neat 'present or absent' response. In 2000, Peacock et al. reported that strains positive for both fibronectin-binding protein (FnBP) A and FnBPB ranged from $85.3 \%$ in endocarditis, $83.9 \%$ in septic arthritis/osteomyelitis and $75.1 \%$ in orthopedic implant-associated infections, down to $63.6 \%$ for nasal carriage isolates [40]. Therefore, even when considering the combination of important adhesins mediating the interaction with fibronectin, the difference between nasal carriage and implant associatedinfections was less than $12 \%$ in frequency. In another more articulated study, the presence of different virulence determinants, including adhesins, toxins, factors implicated in biofilm formation and others, was screened among carriage and invasive isolates [41]. The authors found that seven determinants, among them the genes encoding for three MSCRAMMs (respectively for FnBPA, collagen-binding protein [CNA], and serine-aspartate dipeptide repeat proteins), were significantly more common in invasive isolates. The effect of these genes was cumulative, each independently multiplying the odds of disease. The prevalence of these genes differed from each other by a maximum of $20 \%$ in carriage and in invasive strains. However, this last work opened a new perspective, emphasizing that the virulence potential of each single strain is of multifactorial nature, implying that the recognition of an invasive strain has to rely on a more complex assessment of its virulon.

Therefore, virulence, as a survival strategy adopted by a given strain, is not simply a property associated to a single determinant, but should rather be regarded as the result of a combination of traits, including adhesins, invasins and toxins, whose expression is successfully ruled by appropriate polymorphisms of regulatory genes. In this regard, the accessory gene regulator (agr) locus, associated to the quorum sensing system in $S$. aureus, is known to orchestrate the expression of many toxin genes and adhesion molecules and could therefore play a pivotal role (see Biofilm section).

In line with these considerations, our recent findings point to distinct patterns of virulence genes, which underlie distinct evolutive strategies associated with the polymorphisms of the agr locus in $S$. aureus causing orthopedic implant infections [42]. Isolates presenting different $a g r$ polymorphisms appear to base their survival strategies on diverse alternative adhesins or sets of adhesins. From the analysis of 200 S. aureus isolates derived from implant-related infections, we observed that the isolates belonging to the agr type III was found to be associated with the 
presence of bone sialoprotein-binding protein (Bbp; generally absent in isolates of our collection with agr type I and II groups) and with the copresence of Bbp and CNA. In a further study we compared the frequency of adhesin genes in epidemic and sporadic isolates derived from implant-related orthopedic infections. In the collection we observed that the most prevalent ribogroup was characterized by the tandem arrangement of two adhesin genes, respectively encoding for CNA and Bbp [43]. There is some evidence that in veterinary microbiology the $b b p$ gene, encoding for Bbp, is present only in typical high virulent $S$. aureus strains [44]. It was rather intriguing for us to observe that the most epidemic and successful strain type among biomaterial-associated orthopedic infections is largely represented by isolates endowed with both Bbp and CNA, two adhesins whose respective ligands represent by far the main body of ECM protein components.

The failure of many attempts to ascertain a clear correlation between single molecular determinants and clinical outcomes is lately pushing to a more comprehensive approach, nonlimited to well-defined virulon members, but considering the entire genome, including coding sequences as well as noncoding sequences [45]. Probably, for highly clonal pathogens causing a broad range of diseases, as in the case of $S$. aureus, the complexity is such to implicate different models and infective strategies, each adequate or sufficient for the different conditions of the patients, either healthy and perfectly immunocompetent or with various grades of breached immune defenses. The challenging objective of future genomic and postgenomic eras will be at least to uncover and define the essential and most critical virulence mechanisms among prevailing and most worrying strain types. A better understanding of the role of adhesins and toxins in most prevalent epidemic strains and their added value in terms of acquired virulence will be the most rational approach to elaborate new anti-infective strategies with the largest impact and alternative to antibiotics. In this context, implant infections are particularly relevant because of their impact on the human population in terms of numbers and critical consequences, but also because they originate in tissues where localized immunodepression even offers a chance for less virulent microorganisms to prevail. An implant, as a locus minoris resistentiae, represents an open door that creates the condition for the appearance and the prevalence of new emerging opportunistic species [23].

\section{Biofilm}

In MD-associated infections, after the initial adhesin-mediated biomaterial colonization, S. aureus and S. epidermidis produce biofilm. In biofilm, bacteria encase themselves in an extracellular material ('slime'), which embeds them together and attaches them firmly to the implant surface. The self-produced matrix consists of polysaccharides, proteins and extracellular DNA. In initial studies with coagulase-negative staphylococci the 'slime' production was considered as a virulence factor, especially in $S$. epidermidis $[46,47]$. Then, a high percentage of $S$. aureus strains was also found able to produce the slimy extracellular material, provided that a carbohydrate source was added in the growth medium [48-50].

Biofilm formation proceeds as a four-step process:

- Initial attachment of bacterial cells;

- Accumulation in multiple cell layers;

- Biofilm maturation;

- Detachment of cells from the biofilm into a planktonic state to initiate a new cycle of biofilm formation elsewhere [51].

The initial interactions are nonspecific and mainly hydrophobic in nature [52]. The initial attachment is mediated by specific proteins, the autolysins, first described by Heilmann et al. [53]. In $S$. epidermidis the autolysin/adhesin is AtlE, a $148 \mathrm{kDa}$ protein [53]. In S. aureus the autolysin/adhesin is AtlA, a $137 \mathrm{kDa}$ protein, highly homologous to AtlE [54]. Initial attachment to indwelling MDs is also mediated by MSCRAMMs, which interact with host ECM proteins filming the biomaterial surfaces [31,32].

In the second step, the intercellular adhesion is due to the production of the PIA, which is composed of linear $\beta$-1,6-linked glucosaminylglycan, whose synthesis is mediated by the intercellular adhesion (icaADBC) locus. This locus, initially discovered and investigated in S. epidermidis infections [55,56] and for a long time considered a virulence determinant, was then found to be present also in $S$. aureus [57]. A remarkable prevalence of ica locus in a collection of clinical isolates of $S$. aureus was documented by Arciola et al. [58] . Moreover the ica locus has been found in several other Staphylococcus species and DNA-sequences homologous to the ica locus have been detected in many coagulase-negative staphylococci [59].

Both in S. aureus and in S. epidermidis the expression of the ica operon and the consequent production of biofilm have been shown to depend on several environmental conditions, such as 
culture media composition and supplementation [60], ethanol, salt stress [61] and iron limitation [62]. Also anaerobiosis strongly increased in vitro biofilm expression [63]. Not only environmental stress conditions but also bacterial density regulates biofilm production by means of signal molecules, termed autoinducers, expressed by the quorum sensing system [64]. In staphylococci the regulating system is the agr locus, which is activated during the transition from the exponential growth phase to the stationary growth phase by an autoregulatory mechanism involving a modified pheromone peptide that signals the state of cell density [65]. In $S$. aureus the quorum sensing system agr controls many virulence factors, such as the staphylococcal toxins, the adhesins to collagen, fibronectin and fibrinogen, as well as the synthesis of surface antiphagocytic capsular polysaccharide [66]. However, the role of the agr system on biofilm production is controversial. Basically agr should reduce biofilm production, but according to O'Gara the influence of $a g r$ in biofilm formation can vary from positive to neutral to negative, perhaps reflecting the responsiveness of the quorum sensing system to external environmental influences [67].

The production of biofilm is complex and has been shown to depend on other regulating systems, such as the gene sar that codes for SarA, a staphylococcal protein, which upregulates the production of biofilm by influencing the ica transcription and the production of poly- $N$-acetylglucosamine [68]. Another regulatory system, interconnected with the agr system and implicated in biofilm formation, is constituted by the target of RNAIII-activating peptide, which secretes the peptide RNAIII-activating peptide, whose increase induces biofilm growth [69].

Biofilm production can be alternatively produced via an ica-independent pathway, based on adhesive proteins, such as the biofilm-associated protein, discovered by the research groups of Penadés and Lasa $[70,71]$.

Attention is now pointed to another biofilm matrix component, the eDNA [72,73], which contributes to initial attachment of $S$. epidermidis and also has a role in the accumulative phase of S. epidermidis biofilm formation. In S. epidermidis,
eDNA present in biofilm is similar to genomic DNA and has been shown to originate from lysis of a small subpopulation of bacteria, mediated by AtlE [74]. In S. aureus cell lysis is mediated by murein hydrolases, controlled by $\operatorname{cid} A$ and $\operatorname{lrg} A$ operons [75], which encode proteins similar to holins and antiholins, respectively, and regulate cell lysis in a manner analogous to that observed during bacteriophage-mediated cell lysis [76].

Released eDNA, as well as participating in biofilm development and stabilization, can take an important part in gene transfer mechanisms. This genetic transfer creates an opportunity for the rapid spreading of virulence as well as antibioticresistance genes in circulating strains exposed to the selective pressure of medical treatments [77,78].

Bacteria embedded in biofilms are resistant to antibiotics and disinfectants, to phagocytosis and other armory of the innate and adaptive inflammatory defense systems of the host $[79,80]$.

The escape of bacteria from immune surveillance or antibiotic treatment [81,82] hampers medical treatment and requires implant removal, extensive bone debridement, excision of the infected bone and soft tissues and subsequent prolonged antimicrobial treatment [83].

\section{Future perspective: innovative strategies to combat implant infections Infection-resistant materials}

With the aim to prevent implant-related infections, much research has been performed on the development of anti-infective and infectionresistant biomaterials, such as materials doped with effective antimicrobial drugs or resurfaced to repel bacterial adhesion and new products are continually being proposed for clinical use (Box 2). However, the concentration of bactericidal agents loaded into these biomaterials often raises the possibility of local or systemic toxicity, and the indiscriminate use of prolonged release of antibiotics leads to the potential risk of aiding the appearance of new resistant strains [84-88].

Coating the material surface with a substance able to reduce bacterial adhesion was one of the first attempts to reduce the risk of infection $[89,90]$. Bacterial adhesion on biomaterials may

Box 2. Innovative strategies to combat staphylococcal implant infections.

- New anti-infective, infection-resistant biomaterials and antibiotic-loaded biomaterials are being developed.

- Biofilm-dispersing enzymes: deoxyribonuclease I and dispersin B that are able to attack biofilm components appear rational and promising.

- Currently there are no commercially available anti-S. aureus vaccines for human infection. Microbial surface components recognizing adhesive matrix molecules may represent an ideal target for an antistaphylococcal vaccine.

- Antisense or 'antigene' molecules in the form of peptide nucleic acids able to silence or knock-out bacterial genes responsible for virulence is a possible innovative approach. However, so far peptide nucleic acids offer greater opportunities as biotechnological tools for bacterial detection and gene identification than as therapeutic agents. 
be limited by modulating their hydrophilic properties with variations of polymerization processes or by modifying surfaces with surfactants [91], or by substances or drugs able to hamper the adsorption of proteins onto the biomaterial surfaces [92]. Hydroxyapatite-coated stainless steel orthopedic screws proved as an infection-resistant material [93]. Also chitosan exhibits antiinfective and, at the same time, osteointegration properties [94].

We have in the past indicated that heparin is effective in reducing staphylococcal adhesion $[29,30]$, and we have clarified that the effect of heparin depends on specific inhibition of the binding between fibronectin, the major matrix protein, and a specific $S$. aureus adhesin [95,96].

A self-sterilizing and self-cleaning titanium dioxide $\left(\mathrm{TiO}_{2}\right)$ coating on different device surfaces has been proposed some time ago for its photocatalytic bactericidal mechanism [97] and now the antibacterial applications of $\mathrm{TiO}_{2}$ coatings have again been investigated [98]. The interesting features of $\mathrm{TiO}_{2}$ become even more promising when the length scale of this material is reduced to the nanometer range [99].

Among metals with antimicrobial activity, silver has raised the interest of many investigators because of its good antimicrobial action and low toxicity. Silver-based polymers have been shown to protect the inner and outer surfaces of devices against the attachment of microorganisms [100].

Aiming at using silver together with copper for their antimicrobial effect, avoiding toxic effects, nanometric thin silver and copper films covering less expensive materials has been proposed for their antimicrobial activity [101].

Nanotechnology is now offering innovative approaches: $\mathrm{TiO}_{2}$ nanotubes incorporating silver nanoparticles seem to display long-term antibacterial ability. The $\mathrm{TiO}_{2}$ nanotubes loaded with $\mathrm{Ag}$ nanoparticles were shown to kill all planktonic bacteria during the first days, and the ability to prevent bacterial adhesion is maintained steady for 30 days, a period long enough to prevent postoperation early infection and perhaps even late infection around the implant [102].

Nitric oxide is earning growing interest for its antibacterial effects: sol-gel coatings capable of nitric oxide release have recently been shown to decrease bacterial adhesion and an ingenious application is a sol-gel releasing nitric oxide coating for orthopedic implants [103].

A recent approach aimed at the treatment of mature established biofilms is photodynamic treatment, a process in which microorganisms are treated with a photosensitizer drug and then with low intensity visible light of the appropriate wavelength. The resulting photochemical reactions generate cytotoxic reactive oxygen species, such as single oxygen and free radicals, which are able to exert a bactericidal effect [104-108].

The development of antiadhesive and antiinfective coatings on biomaterials may be expected to have a critical impact in terms of reduced risk of infection, patient morbidity, mortality and health costs.

\section{Antibiotic-loaded biomaterials}

One of the most practiced strategies to prevent and treat the development of implantrelated infections is the use of antibiotic drugs. Antibiotics can be used either systemically, for prophylaxis during the perioperative phase, or locally, delivering them directly at the site of implantation. Local administration of antibiotics has been reported to offer a series of advantages, among them the avoidance of systemic toxicity and the possibility to reach active concentrations where most needed, such as at the interface between implant and tissues. Local delivery can be achieved using biomaterials preloaded in bulk with appropriate antibiotic substances, applying superficial bioactive coatings on prosthetic implant surfaces or using setting cements, gels and other highly viscous vehicle media. Current strategies of achieving convenient kinetics of antibiotic release have been further broadened by the application of nanotechnologies.

The concept of bioactive materials exhibiting antibacterial properties from the combination of biomaterials and antibiotic substances was developed in the early 1950s [109] and rapidly entered clinical use. In surgical fields presenting high risk of infections, surgeons started to treat patients with antibiotic-laden cements or antibiotic-soaked collagen sponges, even when the appearance of patented products on the market was still to come. Therefore, initial use was primarily guided by the good sense of the surgeon. However, in recent years emphasis has been given to the need for evidence-based medicine and the use of antibiotic-loaded biomaterials has been subjected to serious revisions. In a recent article we reviewed the state of the art antibiotic-loaded biomaterials, their great potential, the clinical evidence in favor of their use, and the controversies concerning their possible role in the spread of antibiotic resistance [110]. In orthopedics, the use of antibiotic-laden biomaterials for infection prophylaxis is strongly influenced by the practice of the surgeons, varying broadly in different countries, to use cemented 
or uncemented prostheses. In countries in northern Europe, such as Sweden and Finland where the use of cement for implant fixation is the standard procedure, local delivery of prophylactic antibiotics is regularly practiced.

Ideal antibiotic local delivery systems for prophylaxis of implant infections should use broad-spectrum drugs, release local concentrations well above MICs, but below toxic levels, minimize the period of elution of subinhibitory concentrations, not alter the biocompatibility or interfere with tissue integration, and not evoke allergenic responses. A critical prerequisite is the compatibility of the delivered substance with the biomaterial used as a vehicle. For instance, thermal stability represents a limitation for the incorporation of certain antibiotics in polymethylmethacrylate cements that are largely used in orthopedics for the fixation of prosthetic implants. Moreover, the incorporation of antibiotics can alter the physicochemical structure, finally determining a reduction in the mechanical performance of the implant [111]. However, even the complex interactions taking place at the biomaterial-tissue interface have to be taken into consideration. Thus far, most of the available delivery systems do not meet desirable release kinetics.

Virtually every known antibiotic has been explored for local delivery, from $\beta$-lactams, whose weakness is represented by low thermal stability and limited efficacy for the spread microbial resistance, to glycopeptides such as vancomycin, whose prophylactic use is regarded as highly controversial among epidemiologists. In fact, the use of glycopeptides is justifiable for only selective treatment of infections by multiresistant microorganisms. Aminoglycosides, and in particular gentamicin, are the antibiotics that have been more broadly used for local delivery in orthopedics. However, the spread of antibiotic resistance, especially among staphylococci has significantly affected their efficacious use for prophylaxis and treatment $[4,110]$. Antibioticloaded biomaterials undoubtedly possess a high potential in medicine in the prevention and treatment of infections associated to implants, but nevertheless the growing spread of antibiotic resistances among common opportunistic pathogens represents a severe limitation. Moreover, the frequently observed long-lasting release of subinhibitory amounts of antibiotics from antibioticladen implants is thought to increment even further the prevalence of antibiotic-resistant strains. In light of this, future strategies should be oriented for developing anti-infective biomaterials, exploiting bactericidal molecules alternative to known antibiotics.

\section{Vaccines \& DNA vaccines against adhesins to prevent the first attack of $S$. aureus}

An ideal vaccine should induce antibodies to prevent bacterial colonization in the early stages of infection and promote opsonophagocytic killing by leukocytes. The combination of these effects should control bacterial proliferation and increase the successful attack of bacteria by the immune system.

In the search of the appropriate antigens, a variety of surface/secreted bacterial molecules that are expressed early in infection and respond to the host immune system should be isolated and analyzed. Among the antigens that have a critical role in S. aureus pathogenesis (early adherence to host tissues, role in bacterial growth and effects that neutralize the defense mechanisms of the host) the most promising appear to be the previously mentioned MSCRAMMs, since these adhesins are responsible for the first colonization of bacteria on the surface of implanted MDs, to which biofilm formation follows. Currently there is no efficacious anti-S. aureus vaccine for human infection. The complexity of the organism and the diversity of strains that cause human infection have made the development of a vaccine difficult, if not impossible. Attempts at defining a 'core antigen' for $S$. aureus has not yet yielded a commercially viable target.

Numerous studies have been conducted to assess whether vaccination with MSCRAMM proteins or protein fragments are protective against staphylococcal infection. In an initial study, recombinant fragments of CNA were found to be protective immunogens in a murine model of sepsis [112]. Mice vaccinated with a recombinant form of the A-region of clumping factor A exhibited a reduced arthritic response and a decrease in synovitis and joint destruction in a murine model of $S$. aureus-induced arthritis [113].

Shkreta et al. studied the protective measures of both clumping factor $\mathrm{A}$ and $\mathrm{FnBP}$ as a DNAbased vaccination strategy in a bovine mastitis model, obtaining a cellular and humoral immune response with a partial protection from staphylococcal mastitis and a significant reduction of inflammation and animal distress [114].

Despite the rationale that a vaccine should reach the goal to block the first adherence of staphylococci, PIA has been considered as well. Immunization with poorly acetylated PIA 
conjugated to diphtheria toxin elicited opsonic killing activity against both $S$. epidermidis and $S$. aureus strains and led to a robust and protective response [115], suggesting the potential of this antigen as a broadly effective vaccine for many clinical strains of staphylococci.

The state-of-the-art approach to vaccine prophylaxis against bacterial infection is the 'DNA-vaccine'

This approach originated from 'failed' gene therapy experiments, when mice inoculated with a plasmid expressing human growth hormone elicited antibodies instead of altering growth. Tang et al. reported that an immune response could be elicited by introducing the gene encoding a protein directly into the skin of mice, instead of the antigenic protein itself. They concluded that genetic immunization may be time and labor saving in producing antibodies and may offer a unique method for vaccination [116].

The goal in improving immunogenic performances of DNA vaccines requires precise knowledge of cellular and molecular mechanisms by which DNA vaccines express their immunogenic potential in the human body and requires the choice of appropriate adjuvant elements as crucial molecules for strengthening DNA vaccines [117].

In implant infections caused by $S$. aureus, MSCRAMMs may represent an ideal immunogen for an anti-Staphylococcus vaccine. In fact, they are surface-located, are expressed at a high level both in vitro and in vivo, and play a crucial role as virulence factors. In prosthesis infections, they determine the first phase of anchorage onto biomaterials, which subsequent pathogenetic phases are dependent upon.

A survey of many studies in which staphylococcal MSCRAMMs are utilized in the design of subunit vaccines and in the development of innovative therapeutic strategies that could be implemented following the onset of infection is presented in a recent review by Arciola $e t$ al. From their own experience and from a critical review of the literature, the authors present a "decalogue" for a reasoned selection of target adhesins in designing DNA vaccines against implant infections [118].

\section{Silencing of virulence genes by peptide-nucleic-acid}

The research for novel therapeutic strategies is incited by the emergence of antibiotic-resistant bacteria and the slow progresses in identifying new classes of antimicrobial agents. The adoption of antisense or 'antigene' molecules able to silence or knock-out bacterial genes responsible for their virulence is one possible innovative approach $[119,120]$. The conventional approach based on antisense DNA or RNA oligonucleotides encounters several limitations both in passing through the external bacterial wall and in the rapid degradation by bacterial nucleases.

Antisense molecules that overcome these limitations are peptide nucleic acids (PNAs), in that DNA analogs in which the nucleobases are attached via methylene carbonyl linkages to a peptide chain built up by repeated $N$-(2-aminoethyl) glycine monomers instead of the sugar-phosphate backbone [121,122].

Conditions for the use of PNAs as a therapeutic drugs in silencing virulence genes are an effective delivery of this new substance into bacterial cell, and the identification and choice of an appropriate gene target.

A major problem in the utilization of PNAs in bacteria is their inefficient entry into the targeted pathogen due to the outer membrane barrier. A solution to this problem has come from the knowledge of the mechanism of entry bacterial wall by human defensins or other cationic peptides, such as those expressed by neutrophils, which are able to penetrate and disrupt bacterial membranes.

Good et al. suggested that attachment of a leader cationic peptide to the PNA molecule favors bacterial entry and proposed the amino acid sequence KFFKFFKFFK, attached as a leader peptide to a short PNA (10-12 bases) [121]. This expedient facilitated entry into E. coli, creating a potent antimicrobial effect $[123,124]$.

The reason for the efficacy of this leader peptide and for its usefulness in bacterial entry is its amphipathic structure: the positively charged residues (lysine) preferentially interact with the anionic phospholipids present in the bacterial external membrane (eukaryotic cell membranes are instead characterized by a high content of dipolar phospholipids) and the nonpolar amino acid side chains (phenylalanine) favor attachment to the bacterial external lipid layer.

With regard of the choice of target gene, inhibition of gene expression and of bacterial growth have been achieved in $S$. aureus by targeting the essential genes $f m b B$ (involved in cell wall biosynthesis), $h m r B$ (high methicillin resistance gene), gyrA (involved in DNA replication) and acpP (involved in fatty acid biosynthesis) with PNAs [125,126]. 
The aforementioned examples indicate that PNAs are efficacious agents for inhibiting bacterial growth and for interfering with experimental infections, but silencing or knocking-out bacterial genes by antisense PNAs; however innovative and fascinating, has not yet provided the 'magic bullet' in combating bacteria responsible for implant infections. Although PNAs have been shown to interfere with the expression of basic genes for bacterial growth and with the expression of antibiotic resistance genes, they, so far, offer greater opportunities as biotechnological tools for bacterial detection and gene identification than as therapeutic agents.

\section{Conclusion}

Projections based on the actual trend indicate that the number of arthroplasties is destined to increase in the next decades and implant infections remain the major and often irreducible complication in the clinical use of biomaterials, especially in orthopedics, demanding new therapeutic and preventive strategies. The study and comprehension of virulence factors, their relative weight and their regulatory mechanisms can support new strategies, also at the molecular level, as gene therapies aimed at silencing or knocking out genes responsible for the bacterial implant colonization (adhesins, biofilm production and antibiotic resistance).

\section{Executive summary}

\section{Virulence factors \& pathogenesis of implant infections}

- Implant-related orthopedic infections are typically caused by opportunistic pathogens taking advantage of the presence of foreign bodies that condition the level of the immune defense of host tissues in the immediate proximity.

- The most common bacteria isolated from infected joints are staphylococci. Staphylococcus aureus is the main opportunist pathogen implicated in implant-related infections in most surgical fields, the orthopedic one among them.

- The infecting organisms are either introduced during implantation of a prosthesis or derived from a temporary bacteremia.

- Staphylococci adhere to biomaterials and grow to form a biofilm. The biofilm offers enhanced protection against natural host defenses and antibiotic therapies.

\section{Role of adhesins in the first step of infection}

- Adhesins represent an important group of virulence factors mediating surface adhesive interactions between microbial cells and between these and host cells and the extracellular matrix. They play a primary role, particularly in the early phases of infection pathogenesis of tissue tropism, surface adhesion and colonization.

- The adhesins group includes the cell wall-anchored microbial surface components recognizing adhesive matrix molecules (MSCRAMMs) as well as the more recently described secretable expanded repertoire adhesive molecules (SERAMs). MSCRAMMs, in this differing from SERAMs, are receptorial proteins anchored to the bacterial cell wall through a typical cell wall sorting signal Leu-Pro-X-Thr-Gly (LPXTG) motif.

- The most epidemic and successful clone of $S$. aureus responsible for biomaterial-associated orthopedic infections is endowed with both bone sialoprotein-binding protein and collagen-binding protein, two adhesins whose respective ligands represent by far the main bone extracellular matrix protein components.

\section{Biofilm}

- In medical device-associated infections, after adhesin-mediated initial colonization onto biomaterial, S. aureus and Staphylococcus epidermidis make a use of another virulence factor: the biofilm.

- The major biofilm component is the polysaccharide intercellular adhesin, composed of linear $\beta$-1,6-linked glucosaminylglycan, whose synthesis is mediated by the intercellular adhesion (icaADBC) locus.

- Besides polysaccharide intercellular adhesin, biofilm contains proteins and extracellular DNA.

\section{Innovative strategies to combat Staphylococcal implant infections}

- With the aim to prevent implant-related infections, anti-infective and infection-resistant biomaterials are being developed. New products are continually being proposed for clinical use, among which are antibiotic-loaded biomaterials.

- Among many agents taken into consideration for staphylococcal biofilm disruption, enzymes able to attack biofilm components appear rational and promising. Two well-studied biofilm-dispersing enzymes are deoxyribonuclease I and dispersin B.

- Currently there are no commercially available anti-S. aureus vaccines for human infection. In implants, infections caused by S. aureus MSCRAMMs may represent an ideal target for an antistaphylococcal vaccine. In fact, they are surface-located, are expressed at a high level both in vitro and in vivo and play a crucial role as virulence factors. In prosthesis infections, they determine the first phase of anchorage onto biomaterials, which all the other pathogenetic phases are dependent upon.

- The research for novel therapeutic strategies is incited by the emergence of antibiotic-resistant bacteria and the slow progress in identifying new classes of antimicrobial agents. The adoption of antisense or 'antigene' molecules able to silence or knock-out bacterial genes responsible for virulence is a possible innovative approach. Antisense molecules in the form of peptide nucleic acids have been shown to interfere with the expression of basic genes for bacterial growth and with the expression of antibiotic resistance genes, but so far, peptide nucleic acids offer greater opportunities as biotechnological tools for bacterial detection and gene identification than as therapeutic agents. 
Development of immunological approaches (blocking early bacterial adhesion) or the use of enzymes that interfere with the biosynthesis or the activity of specific biofilm components or able to disrupt formed biofilms may prove to be useful in preventing or treating infections compromising the success of MDs [127]. However, because staphylococcal infections involve multiple virulence determinants, it is unlikely that a single strategy against a specific target will protect the host from the infection. The synergistic use of immunotherapy or drugs in combination with traditional or new antibiotics could broaden the clinical options and improve the effectiveness of antimicrobial therapy.

\section{Financial \& competing interests disclosure}

The authors have no relevant affiliations or financial involvement with any organization or entity with a financial interest in or financial conflict with the subject matter or materials discussed in the manuscript. This includes employment, consultancies, honoraria, stock ownership or options, expert testimony, grants or patents received or pending, or royalties.

No writing assistance was utilized in the production of this manuscript.

\section{Bibliography}

Papers of special note have been highlighted as: - of interest

1. Serra-Sutton V, Allepuz A, Espallargues M, Labek G, Pons JM. Arthroplasty registers: a review of international experiences. Int. J. Technol. Assess Health Care 25, 63-72 (2009).

2. Kurtz S, Ong K, Lau E et al. Projections of primary and revision hip and knee arthroplasty in the United States from 2005 to 2030. J. Bone. Joint. Surg. Am. 89, 780-785 (2007).

3. An YH, Friedman RJ. Concise review of mechanisms of bacterial adhesion to biomaterial surfaces. J. Biomed. Mater. Res. 43, 338-348 (1998).

4. Campoccia D, Montanaro L, Arciola CR. The significance of infection related to orthopedic devices and issues of antibiotic resistance Biomaterials 27, 2331-2339 (2006).

- Offers an overview of the complexity of the current and new promising strategies in the field of biomaterials to reduce the risks and counteract the establishment of implant infections.

5. Zimmerli W, Waldvogel FA, Vaudaux P et al. Pathogenesis of foreign body infection: description and characteristics of an animal model. J. Infect. Dis. 146, 487-497 (1982).

6. Murdoch DR, Roberts SA, Fowler VG Jr et al. Infection of orthopedic prostheses after Staphylococcus aureus bacteremia. Clin. Infect. Dis. 32, 647-649 (2001).

7. Lalani T, Chu VH, Grussemeyer CA et al. Clinical outcomes and costs among patients with Staphylococcus aureus bacteremia and orthopedic device infections. Scand. J. Infect. Dis. 40(11-12), 973-977 (2008).

8. Sendi P, Banderet F, Graber P et al. Periprosthetic joint infection following Staphylococcus aureus bacteremia. J. Infect. 63(1), 17-22 (2011).
9. Sculco TP. The economic impact of infected total joint arthroplasty. Instr. Course Lect. 42, 349-351 (1993).

10. Katz JN, Losina E, Barrett J et al. Association between hospital and surgeon procedure volume and outcomes of total hip replacement in the United States Medicare population. J. Bone Joint Surg. Am. 83, 1622-1629 (2001).

11. Mahomed NN, Barrett J, Katz JN et al. Epidemiology of total knee replacement in the United States Medicare population. J. Bone Joint Surg. Am. 87, 1222-1228 (2005).

12. Jämsen E, Furnes O, Engesaeter LB et al. Prevention of deep infection in joint replacement surgery. Acta Orthop. 81, 660-666 (2010).

13. Phillips JE, Crane TP, Noy M et al. The incidence of deep prosthetic infections in a specialist orthopaedic hospital: a 15-year prospective survey. J. Bone Joint Surg. Br. 88, 943-948 (2006).

14. Pulido L, Ghanem E, Joshi A et al. Periprosthetic joint infection: the incidence, timing, and predisposing factors. Clin. Orthop. Relat. Res. 466, 1710-1715 (2008).

15. Jämsen $\mathrm{E}$, Varonen $\mathrm{M}$, Huhtala $\mathrm{H}$ et al. Incidence of prosthetic joint infections after primary knee arthroplasty. J. Arthroplasty 25, 87-92 (2010).

16. Jämsen E, Huotari K, Huhtala $\mathrm{H}$ et al. Low rate of infected knee replacements in a nationwide series - is it an underestimate? Acta Orthop. 80, 205-212 (2009).

17. Huotari K, Lyytikäinen O, Ollgren JV et al. Hospital Infection Surveillance Team. Disease burden of prosthetic joint infections after hip and knee joint replacement in Finland during 1999-2004: capturerecapture estimation. J. Hosp. Infect. 75, 205-208 (2010).

18. Leone JM, Hanssen AD. Management of infection at the site of a total knee arthroplasty. Instr. Course Lect. 55, 449-461 (2006).
19. Zimmerli W, Trampuz A, Ochsner PE. Prosthetic-joint infections. N. Engl. J. Med. 351, 1645-1654 (2004).

- Focuses on the pathogenesis, diagnosis and treatment of infections associated with prosthetic joints.

20. Tsukayama DT, Goldberg VM, Kyle R. Diagnosis and management of infection after total knee arthroplasty. J. Bone Joint Surg. Am. 85-A (Suppl. 1), S75-S80 (2003).

21. Arciola CR, An YH, Campoccia D et al. Etiology of implant orthopedic infections: a survey on 1027 clinical isolates. Int. J. Artif. Organs. 28, 1091-1100 (2005).

- The spectrum and the prevalence of the bacteria most frequently involved in orthopedic infections are explored here, with particular reference to those infections associated with implant biomaterials, which were grouped based on device typology.

22. Boles BR, Horswill AR. Staphylococcal biofilm disassembly. Trends Microbiol. 19(9), 449-455 (2011).

23. von Eiff C, Arciola CR, Montanaro L et al. Emerging Staphylococcus species as new pathogens in implant infections. Int. J. Artif. Organs. 29, 360-367 (2006).

24. Jarraud S, Mougel C, Thioulouse J et al. Relationships between Staphylococcus aureus genetic background, virulence factors, agr groups (alleles), and human disease. Infect. Immun. 70, 631-641 (2002).

25. Otto M. A MRSA-terious enemy among us: end of the PVL controversy? Nat. Med. 17, 169-170 (2011).

26. Sittka A, Vogel J. A glimpse at the evolution of virulence control. Cell. Host. Microbe. 4, 310-312 (2008).

27. Fleer A, Timmerman CP, Besnier JM et al. Surface proteins of coagulase-negative staphylococci: their role in adherence to biomaterials and in opsonization. J. Biomater. Appl. 5, 154-165 (1990). 
28. Gristina AG. Biomaterial-centered infection: microbial adhesion versus tissue integration. Science 237(4822), 1588-1595 (1987).

- A pioneer study: modifications to biomaterial surfaces at an atomic level will allow the programming of cell-tosubstratum events, thereby diminishing infection by enhancing tissue compatibility or integration, or by directly inhibiting bacterial adhesion.

29. Arciola CR, Radin L, Alvergna P et al. Heparin surface treatment of poly(methylmethacrylate) alters adhesion of a Staphylococcus aureus strain: utility of bacterial fatty acid analysis. Biomaterials 14, 1161-1164 (1993).

30. Arciola CR, Caramazza R, Pizzoferrato A. In vitro adhesion of Staphylococcus epidermidis on heparin-surface-modified intraocular lenses. J. Cataract Refract. Surg. 20, 158-161 (1994).

31. Patti JM, Allen BL, McGavin MJ et al. MSCRAMM-mediated adherence of microorganisms to host tissues. Annu. Rev. Microbiol. 48, 585-617 (1994).

- Focuses on a class of cell surface adhesins that specifically interact with extracellular matrix components designated microbial surface components recognizing adhesive matrix molecules (MSCRAMMs).

32. Speziale P, Pietrocola G, Rindi S et al. Structural and functional role of Staphylococcus aureus surface components recognizing adhesive matrix molecules of the host. Future Microbiol. 4, 1337-1352 (2009).

- Describes the MSCRAMMs in terms of structural organization and ligand-binding capacity and discusses their role as a possible target for immunotherapy.

33. Chavakis T, Wiechmann K, Preissner KT et al. Staphylococcus aureus interactions with the endothelium: the role of bacterial "secretable expanded repertoire adhesive molecules" (SERAM) in disturbing host defense systems. Thromb. Haemost. 94, 278-285 (2005).

34. Suree N, Liew CK, Villareal VA et al. The structure of the Staphylococcus aureus sortase-substrate complex reveals how the universally conserved LPXTG sorting signal is recognized. J. Biol. Chem. 284, 24465-24477 (2009).

35. Montanaro L, Arciola CR, Borsetti E et al. A polymerase chain reaction (PCR) method for the identification of collagen adhesin gene (cna) in Staphylococcus-induced prosthesis infections. New Microbiol. 21, 359-363 (1998).

36. Montanaro L, Arciola CR, Baldassarri L et al. Presence and expression of collagen adhesin gene (cna) and slime production in Staphylococcus aureus strains from orthopaedic prosthesis infections. Biomaterials 20, 1945-1949 (1999).
37. Montanaro L, Arciola CR, Borsetti E et al. Detection of fibronectin-binding protein genes in staphylococcal strains from peri-prosthesis infections. New Microbiol. 22, 331-336 (1999).

38. Arciola CR, Campoccia D, Gamberini S et al. Presence of fibrinogen-binding adhesin gene in Staphylococcus epidermidis isolates from central venous catheters-associated and orthopaedic implant-associated infections. Biomaterials 25, 4825-4829 (2004).

39. Arciola CR, Campoccia D, Gamberini S et al. Prevalence of $c n a, f n b A$ and $f n b B$ adhesin genes among Staphylococcus aureus isolates from orthopedic infections associated to different types of implant. FEMS Microbiol. Lett. 246, 81-86 (2005).

40. Peacock SJ, Day NP, Thomas MG et al. Clinical isolates of Staphylococcus aureus exhibit diversity in $f n b$ genes and adhesion to human fibronectin. J. Infect. 41, 23-31 (2000).

41. Peacock SJ, Moore CE, Justice A et al. Virulent combinations of adhesin and toxin genes in natural populations of Staphylococcus aureus. Infect. Immun. 70, 4987-4996 (2002).

42. Montanaro L, Speziale P, Campoccia D et al. Polymorphisms of agr locus correspond to distinct genetic patterns of virulence in Staphylococcus aureus clinical isolates from orthopedic implant infections. J. Biomed. Mater. Res. A. 94, 825-832 (2010).

43. Campoccia D, Speziale P, Ravaioli S et al. The presence of both bone sialoproteinbinding protein gene and collagen adhesin gene as a typical virulence trait of the major epidemic cluster in isolates from orthopedic implant infections. Biomaterials 30 , 6621-6628 (2009).

- Suggests that specific adhesins may synergistically act in the onset of implant infections and that anti-adhesin strategies should be targeted to adhesins conjointly present.

44. Vancraeynest K, Hermans F, Haesebrouck F et al. Genotypic and phenotypic screening of high and low virulence Staphylococcus aureus isolates from rabbits for biofilm formation and MSCRAMMs. Vet. Microbiol. 103, 241-247 (2004).

45. Lazarevic V, Beaume M, Corvaglia A et al. Epidemiology and virulence insights from MRSA and MSSA genome analysis. Future Microbiol. 6, 513-532 (2011).

46. Arciola CR, Campoccia D, Gamberini S et al. Occurrence of ica genes for slime synthesis in a collection of Staphylococcus epidermidis strains from orthopedic prosthesis infections. Acta. Orthop. Scand. 74, 617-621 (2003).
47. Arciola CR, Baldassarri L, Montanaro L. In catheter infections by Staphylococcus epidermidis the intercellular adhesion (ica) locus is a molecular marker of the virulent slime-producing strains. J. Biomed. Mater. Res. 59, 557-562 (2002).

48. Ammendolia MG, Di Rosa R, Montanaro L et al. Slime production and expression of the slime-associated antigen by staphylococcal clinical isolates. J. Clin. Microbiol. 37, 3235-3238 (1999).

- The ability to produce slime and to express a slime-associated antigen was examined in a collection of staphylococcal clinical isolates. For the first time, a high percentage of Staphylococcus aureus strains were shown to produce biofilm expolysaccharide.

49. McKenney D, Pouliot KL, Wang Y, et al. Broadly protective vaccine for Staphylococcus aureus based on an in vivo-expressed antigen. Science 284, 1523-1527. (1999).

50. Costerton JW, Stewart PS, Greenberg EP. Bacterial biofilms: A common cause of persistent infections. Science 284, 1318-1322 (1999).

51. Mack D, Becker P, Chatterjee I et al. Mechanisms of biofilm formation in Staphylococcus epidermidis and Staphylococcus aureus: functional molecules, regulatory circuits, and adaptive responses. Int. J. Med. Microbiol. 294, 203-212 (2004).

- Factors functional in biofilm formation, their role in pathogenesis and regulation of their expression are presented.

52. Legeay G, Poncin-Epaillard F, Arciola CR. New surfaces with hydrophilic/hydrophobic characteristics in relation to (no)bioadhesion. Int. J. Artif. Organs. 29, 453-461 (2006).

53. Heilmann C, Hussain M, Peters G et al. Evidence for autolysin-mediated primary attachment of Staphylococcus epidermidis to a polystyrene surface. Mol. Microbiol. 24, 1013-1024 (1997).

54. Foster SJ. Molecular characterization and functional analysis of the major autolysin of Staphylococcus aureus 8325/4. J. Bacteriol. 177, 5723-5725 (1995).

55. Heilmann C, Schweitzer O, Gerke C et al. Molecular basis of intercellular adhesion in the biofilm-forming Staphylococcus epidermidis. Mol. Microbiol. 20, 1083-1091 (1996).

56. Gerke C, Kraft A, Sussmuth R et al. Characterization of the $N$-acetylglucosaminyltransferase activity involved in the biosynthesis of the Staphylococcus epidermidis polysaccharide intercellular adhesin. J. Biol. Chem. 273, 18586-18593 (1998). 
- The polysaccharide intercellular adhesin (PIA) is an important factor in the colonization of medical devices by Staphylococcus epidermidis. The genes encoding PIA production are organized in the icaADBC operon.

57. Cramton, SE, Gerke C, Schnell NF et al. The intercellular adhesion (ica) locus is present in Staphylococcus aureus and is required for biofilm formation. Infect. Immun. 67, 5427-5433 (1999).

58. Arciola CR, Baldassarri L, Montanaro L. Presence of $i c a A$ and $i c a D$ genes and slime production in a collection of staphylococcal strains from catheter-associated infections. J. Clin. Microbiol. 39, 2151-2156 (2001).

59. Mack D, Rohde H, Harris LG et al. Biofilm formation in medical device-related infection. Int. J. Artif. Organs 9, 343-359 (2006).

60. Rohde H, Knobloch JK, Horstkotte MA et al. Correlation of biofilm expression types of Staphylococcus epidermidis with polysaccharide intercellular adhesin synthesis: evidence for involvement of icaADBC genotype-independent factors. Med. Microbiol. Immunol. 190, 105-112 (2001).

61. Knobloch JK, Bartscht K, Sabottke A et al. Biofilm formation by Staphylococcus epidermidis depend on functional RsbU, an activator of the $\operatorname{sig} B$ operon: Differential activation mechanisms due to ethanol and salt stress. J. Bacteriol. 183, 2624-2633 (2001).

62. Bertuccini L, Ammendolia MG et al. Effect of iron limitation on biofilm production by Staphylococcus aureus. Eur. J. Clin. Microbiol. Infect. Dis. 20, 343-345 (2001).

63. Cramton SE, Ulrich M, Götz F et al. Anaerobic conditions induce expression of polysaccharide intercellular adhesin in Staphylococcus aureus and Staphylococcus epidermidis. Infect. Immun. 69, 4079-4085 (2002).

64. Novick RP, Muir TW. Virulence gene regulation by peptides in staphylococci and other gram-positive bacteria. Curr. Opin. Microbiol. 2, 40-45 (1999).

65. Costerton JW, Montanaro L, Arciola CR. Bacterial communications in implant infections: a target for an intelligence war. Int. J. Artif. Organs 30, 757-763 (2007).

66. Novick RP. Autoinduction and signal transduction in the regulation of staphylococcal virulence. Mol. Microbiol. 48, 1429-1449 (2003).

67. O'Gara JP. ica and beyond: biofilm mechanisms and regulation in Staphylococcus epidermidis and Staphylococcus aureus. FEMS Microbiol. Lett. 270, 179-188 (2007).
68. Beenken KE, Dunman PM, McAleese F et al. Global gene expression in Staphylococcus aureus biofilms. J. Bacteriol. 186, 4665-4684. (2004).

69. Korem M, Gov Y, Kiran MD et al. Transcriptional profiling of RNA III activating protein, a master regulator of staphylococcal virulence. Infect. Immun. 73, 6220-6228 (2005)

70. Latasa C, Solano C, Penadés JR et al. Biofilm-associated proteins. C. R. Biol. 329, 849-857 (2006).

71. Lasa I, Penadés JR. Bap. a family of surface proteins involved in biofilm formation. Res. Microbiol. 157, 99-107 (2006).

72. Whitchurch CB, Tolker-Nielsen T, Ragas PC et al. Extracellular DNA required for bacterial biofilm formation. Science 295 (5559), 1487 (2002).

73. Mann EE, Rice KC, Boles BR et al. Modulation of eDNA release and degradation affects Staphylococcus aureus biofilm maturation. PLoS ONE 4, e5822 (2009).

74. Qin Z, Ou Y, Yang L, Zhu Y et al. Role of autolysin-mediated DNA release in biofilm formation of Staphylococcus epidermidis. Microbiol. 153, 2083-2092 (2007).

75. Rice, KC, Mann EE, Endres JL et al. The cidA murein hydrolase regulator contributes to DNA release and biofilm development in Staphylococcus aureus. Proc. Natl Acad. Sci. USA 104, 8113-8118 (2007).

76. Ranjit DK, Endres JL, Bayles KW. Staphylococcus aureus CidA and LrgA proteins exhibit holin-like properties. J. Bacteriol. 193 , 2468-2476 (2011).

77. Wu J, Xi C. Evaluation of different methods for extracting extracellular DNA from the biofilm matrix. Appl. Environ. Microbiol. 75(16), 5390-5395 (2009).

78. Molin S, Tolker-Nielsen T. Gene transfer occurs with enhanced efficiency in biofilms and induces enhanced stabilisation of the biofilm structure. Curr. Opin. Biotechnol. 14(3), 255-61 (2003).

79. Arciola CR. Host defense against implant infection: the ambivalent role of phagocytosis. Int. J. Artif. Organs. 33, 565-567 (2010).

80. Thurlow LR, Hanke ML, Fritz T et al. Staphylococcus aureus biofilms prevent macrophage phagocytosis and attenuate inflammation in vivo. J. Immunol. 186 , 6585-6596 (2011).

81. Darouiche RO. Treatment of infections associated with surgical implants. $N$. Engl. J. Med. 350, 1422-1429 (2004).

82. Stewart PS, Costerton JW. Antibiotic resistance of bacteria in biofilms. Lancet 358, 135-138 (2001).
83. Toms AD, Davidson D, Masri BA et al. The management of peri-prosthetic infection in total joint arthroplasty. J. Bone Joint Surg. Br. 88, 149-155 (2006).

84. Arciola CR, Alvi FI, An YH et al. Implant infection and infection resistant materials: a mini review. Int. J. Artif. Organs. 28, 1119-1125 (2005).

85. Williams JF, Worley SD. Infection-resistant nonleachable materials for urologic devices. J. Endourol. 14, 395-400 (2000).

86. von Eiff C, Kohnen W, Becker K et al. Modern strategies in the prevention of implant-associated infections. Int. J. Artif. Organs 28, 11469-11565 (2005).

87. Langlais F, Belot N, Ropars M et al. Antibiotic cements in articular prostheses: current orthopaedic concepts. Int. J. Antimicrob. Agents 28, 84-89 (2006).

88. Dunne $\mathrm{N}, \mathrm{Hill} \mathrm{J}, \mathrm{McAfee} \mathrm{P}$ et al. In vitro study of the efficacy of acrylic bone cement loaded with supplementary amounts of gentamicin: effect on mechanical properties, antibiotic release, and biofilm formation. Acta Orthop. 78, 774-785 (2007).

89. Arciola CR, Maltarello MC, Cenni E et al. Disposable contact lenses and bacterial adhesion. In vitro comparison between ionic/ high-water-content and non-ionic/low-water content lenses. Biomaterials 16, 685-690 (1995).

90. Arciola CR, Montanaro L, Caramazza R et al. Inhibition of bacterial adherence to a high-water-content polymer by a watersoluble, nonsteroidal, anti-inflammatory drug. J. Biomed. Mater. Res. 42, 1-5 (1998).

91. Singh P, Cameotra SS. Potential applications of microbial surfactants in biomedical sciences. Trends Biotechnol. 22, 142-146 (2004).

92. Levy ML, Luu T, Meltzer HS et al. Bacterial adhesion to surfactant-modified silicone surfaces. Neurosurgery 54, 488-490 (2004).

93. Arciola CR, Montanaro L, Giordano M et al. Hydroxyapatite-coated orthopaedic screws as infection resistant materials: in vitro study. Biomaterials 20, 323-327 (1999).

94. Di Martino A, Sittinger M, Risbud MV. Chitosan: a versatile biopolymer for orthopaedic tissue-engineering. Biomaterials 26, 5983-5990 (2005).

95. Arciola CR, Bustanji Y, Conti M et al. Staphylococcus epidermidis-fibronectin binding and its inhibition by heparin. Biomaterials 24, 3013-3019 (2003).

- The binding of S. epidermidis to fibronectin and the effect of heparin on this interaction were studied by dynamic force spectroscopy. A single molecular binding site of fibronectin is involved in 
the interaction with $S$. epidermidis near the $\mathrm{C}$-terminus, and it is specifically inhibited by heparin.

96. Bustanji Y, Arciola CR, Conti M et al. Dynamics of the interaction between a fibronectin molecule and a living bacterium under mechanical force. Proc. Natl Acad. Sci. USA 100, 13292-13297 (2003).

97. Ohko Y, Utsumi Y, Niwa C et al. Selfsterilizing and self-cleaning of silicone catheters coated with $\mathrm{TiO}(2)$ photocatalyst thin films: a preclinical work. J. Biomed. Mater. Res. 58, 97-101 (2001).

98. Petrini, P, Arciola CR, Pezzali I et al. Antibacterial activity of zinc modified titanium oxide surface. Int. J. Artif. Organs 29, 434-442 (2006).

99. Wu Y, Yu J, Liu HM et al. One-dimensional $\mathrm{TiO}_{2}$ nanomaterials: preparation and catalytic applications. J. Nanosci. Nanotechnol. 10, 6707-6719 (2010).

100. Monteiro DR, Gorup LF, Takamiya AS et al. The growing importance of materials that prevent microbial adhesion: antimicrobial effect of medical devices containing silver. Int. J. Antimicrob. Agents 34, 103-110 (2009).

101. Codita I, Caplan DM, Dragulescu EC et al. Antimicrobial activity of copper and silver nanofilms on nosocomial bacterial species. Roum. Arch. Microbiol. Immunol. 69, 204-212 (2010).

102. Zhao L, Wang H, Huo K et al. Antibacterial nano-structured titania coating incorporated with silver nanoparticles. Biomaterials 32, 5706-5716 (2011).

103. Nablo BJ, Rothrock AR, Schoenfisch MH. Nitric oxide releasing sol-gels as antibacterial coatings for orthopedic implants. Biomaterials 26, 917-924 (2005).

104. Jori G. Photodynamic therapy of microbial infections: state of the art and perspectives. J. Environ. Pathol. Toxicol. Oncol. 25, 505-519 (2006).

105. Sharma M, Visai L, Bragheri F et al. Toluidine blue-mediated photodynamic effects on staphylococcal biofilms. Antimicrob. Agents Chemother. 52, 299-305 (2008).

106. Di Poto A, Sbarra MS, Provenza G et al. The effect of photodynamic treatment combined with antibiotic action or host defence mechanisms on Staphylococcus aureus biofilms. Biomaterials 30, 3158-3166 (2009).

107. Sbarra MS, Arciola CR, Di Poto A et al. The photodynamic effect of tetra-substituted $\mathrm{N}$-methyl-pyridyl-porphine combined with the action of vancomycin or host defense mechanisms disrupts Staphylococcus epidermidis biofilms. Int. J. Artif. Organs. 32, 574-583 (2009).
108. Saino E, Sbarra MS, Arciola CR et al. Photodynamic action of Tri-meso ( $N$-methyl-pyridyl), meso ( $N$-tetradecylpyridyl) porphine on Staphylococcus epidermidis biofilms grown on Ti6Al4V alloy. Int. J. Artif. Organs. 33, 636-645 (2010).

109. Colton MB, Ehrlich E. Bactericidal effect obtained by addition of antibiotics to dental cements and direct filling resins. J. Am. Dent. Assoc. 47, 524-531 (1953).

110. Campoccia D, Montanaro L, Speziale P et al. Antibiotic-loaded biomaterials and the risks for the spread of antibiotic resistance following their prophylactic and therapeutic clinical use. Biomaterials 31, 6363-6377 (2010).

- The use of antibiotic-loaded biomaterials in uninfected tissues to prevent implant infections is controversial. Prolonged release of prophylactic inhibitory or subinhibitory amounts of antibiotics raises concerns for their possible contribution to enhancing biofilm formation and selecting resistant mutants.

111. Dunne NJ, Hill J, McAfee P et al. Incorporation of large amounts of gentamicin sulphate into acrylic bone cement: effect on handling and mechanical properties, antibiotic release, and biofilm formation. Proc. Inst. Mech. Eng. H. 222, 355-365 (2008).

112. Nilsson IM, Patti JM, Bremell T et al. Vaccination with a recombinant fragment of collagen adhesin provides protection against Staphylococcus aureus mediated septic death. J. Clin. Invest. 101, 2640-2649 (1998).

113. Josefsson E, Hartford O, O'Brien L et al. Protection against experimental Staphylococcus aureus arthritis by vaccination with clumping factor $A$, a novel virulence determinant. J. Infect. Dis. 184, 1572-1580 (2001).

114. Shkreta L, Talbot BG, Diarra MS et al. Immune responses to a DNA/protein vaccination strategy against Staphylococcus aureus induced mastitis in dairy cows. Vaccine 23, 114-126 (2004).

115. Maira-Litran T, Kropec A, Goldmann D et al. Biologic properties and vaccine potential of the staphylococcal poly- $N$-acetyl glucosamine surface polysaccharide. Vaccine 22, 872-879 (2004).

116. Tang D, Devit M, Johnston SA. Genetic immunization is a simple method for eliciting an immune response. Nature 356, 152-154 (1992).

117. Coban C, Koyama S, Takeshita F et al. Molecular and cellular mechanisms of DNA vaccines. Hum. Vaccin. 4, 453-456 (2008).
118. Arciola CR, Speziale P, Montanaro L. Perspectives on DNA vaccines. Targeting staphylococcal adhesins to prevent implant infections. Int. J. Artif. Organs. 32, 635-641 (2009).

119. Arciola CR. New concepts and new weapons in implant infections. Int. J. Artif. Organs. 32, 533-536 (2009).

120. Costerton WJ, Montanaro L, Balaban N et al. Prospecting gene therapy of implant infections. Int. J. Artif. Organs. 32, 689-695 (2009).

121. Good L, Awasthi SK, Dryselius R et al. Bactericidal antisense effects of peptide-PNA conjugates. Nat. Biotechnol. 19, 360-364 (2001).

122. Ray A, Nordén B. Peptide nucleic acid (PNA): its medical and biotechnical applications and promise for the future. FASEB J. 14, 1041-1060 (2000).

123. Lundin KE, Good L, Strömberg R et al. Biological activity and biotechnological aspects of peptide nucleic acid. Adv. Genet. 56, 1-51 (2006).

124. Nekhotiaeva N, Awasthi SK, Nielsen PE et al. Inhibition of Staphylococcus aureus gene expression and growth using antisense peptide nucleic acids. Mol. Ther. 10, 652-659 (2004). Comment in: Mol. Ther. 10, 614-615 (2004).

125. Kurupati P, Tan KS, Kumarasinghe G. et al. Inhibition of gene expression and growth by antisense peptide nucleic acids in a multiresistant $\beta$-lactamase-producing Klebsiella pneumoniae strain. Antimicrob. Agents Chemother. 51, 805-811 (2007).

126. Tan XX, Actor JK, Chen Y. Peptide nucleic acid antisense oligomer as a therapeutic strategy against bacterial infection: proof of principle using mouse intraperitoneal infection. Antimicrob. Agents Chemother. 49, 3203-3207 (2005).

127. Montanaro L, Campoccia D, Arciola CR. Advancements in molecular epidemiology of implant infections and future perspectives. Biomaterials 28, 5155-5168 (2007).

- The authors comment on the range of molecular techniques available, reviewing the various applications of molecular epidemiology to study the implant infections and provide some experimental examples related to the field of orthopedic implant infections.

128. Zong Y, Xu Y, Liang X et al. A 'Collagen Hug' model for Staphylococcus aureus CNA binding to collagen. EMBO J. 24, 4224-4236 (2005). Erratum in: EMBO J. 25, 921 (2006).

129. Patti JM, Bremell T, Krajewska-Pietrasik D et al. The Staphylococcus aureus collagen adhesin is a virulence determinant in experimental septic arthritis. Infect. Immun. 62, 152-161 (1994). 
130. Mascari LM, Ross JM. Quantification of staphylococcal-collagen binding interactions in whole blood by use of a confocal microscopy shear-adhesion assay. J. Infect. Dis. 188, 98-107 (2003).

131. Patti JM, Boles JO, Hook M. Identification and biochemical characterization of the ligand binding domain of the collagen adhesin from Staphylococcus aureus. Biochem. 32, 1142811435 (1993).

132. Elasri MO, Thomas JR, Skinner RA et al. Staphylococcus aureus collagen adhesin contributes to the pathogenesis of osteomyelitis. Bone 30, 275-280 (2002).

133. Rhem MN, Lech EM, Patti JM et al. The collagen-binding adhesin is a virulence factor in Staphylococcus aureus keratitis. Infect. Imm. 68, 3776-3779 (2000).

134. Fitzgerald JR, Loughman A, Keane F et al. Fibronectin-binding proteins of Staphylococcus aureus mediate activation of human platelets via fibrinogen and fibronectin bridges to integrin GPIIb/IIIa and IgG binding to the Fc $\gamma$ RIIa receptor. Mol. Microbiol. 59, 212-230 (2006).

135. Fowler T, Wann ER, Joh D et al. Cellular invasion by Staphylococcus aureus involves a fibronectin bridge between the bacterial fibronectin-binding MSCRAMMs and host cell $\beta 1$ integrins. Eur. J. Cell. Biol. 79, 672-679 (2000).

136. Piroth L, Que YA, Widmer E et al. The fibrinogen- and fibronectin-binding domains of Staphylococcus aureus fibronectin-binding protein A synergistically promote endothelial invasion and experimental endocarditis. Infect. Imm. 76, 3824-3831 (2008).

137. Heying R, van de Gevel J, Que YA et al. Contribution of (sub) domains of Staphylococcus aureus fibronectin-binding protein to the proinflammatory and procoagulant response of human vascular endothelial cells. Thromb. Haemost. 101, 495-504 (2009).

138. O’Neill E, Pozzi C, Houston P et al. A novel Staphylococcus aureus biofilm phenotype mediated by the fibronectin-binding proteins, FnBPA and FnBPB. J. Bacteriol. 190, 3835-3850 (2008).

139. Que YA, Haefliger JA, Piroth L et al. Fibrinogen and fibronectin binding cooperate for valve infection and invasion in Staphylococcus aureus experimental endocarditis. J. Exp. Med. 201, 1627-1635 (2005).

140. Pishchany G, McCoy AL, Torres VJ et al. Specificity for human hemoglobin enhances Staphylococcus aureus infection. Cell Host Microbe 8, 544-550 (2010).

141. Clarke SR, Foster SJ. IsdA protects Staphylococcus aureus against the bactericidal protease activity of apolactoferrin. Infect. Immun. 76, 1518-1526 (2008).

142. Corrigan RM, Miajlovic H, Foster TJ. Surface proteins that promote adherence of Staphylococcus aureus to human desquamated nasal epithelial cells. $B M C$ Microbiol. 9, 22-32 (2009).

143. Reniere ML, Skaar EP. Staphylococcus aureus haem oxygenases are differentially regulated by iron and haem. Mol. Microbiol. 69, 1304-1315 (2008).

144. Cheng AG, Kim HK, Burts ML et al. Genetic requirements for Staphylococcus aureus abscess formation and persistence in host tissues. FASEB J. 23, 3393-3404 (2009).

145. Torres VJ, Pishchany G, Humayun M et al. Staphylococcus aureus Is $\mathrm{dB}$ is a hemoglobin receptor required for heme iron utilization. J. Bacteriol. 188, 8421-8429 (2006).

146. Clarke SR, Brummell KJ, Horsburgh MJ et al. Identification of in vivo-expressed antigens of Staphylococcus aureus and their use in vaccinations for protection against nasal carriage. J. Infect. Dis. 193, 1098-1108 (2006).

147. Bragado R, López de Castro JA, Juárez C et al. The effect of the chemical modification in human Fc $\gamma$ fragment on protein $A$ and $F_{c}$ receptor binding. Immunol. Lett. 5, 239-245 (1982).

148. Atkins KL, Burman JD, Chamberlain ES et al. S. aureus IgG-binding proteins $\mathrm{SpA}$ and Sbi: host specificity and mechanisms of immune complex formation. Mol. Immunol. 45, 1600-1611 (2008).

149. Bekeredjian-Ding I, Inamura S, Giese T et al. Staphylococcus aureus protein A triggers $\mathrm{T}$ cell-independent $\mathrm{B}$ cell proliferation by sensitizing B cells for TLR2 ligands. J. Immunol. 178, 2803-2812 (2007).

150. Nguyen T, Ghebrehiwet B, Peerschke EI. Staphylococcus aureus protein A recognizes platelet $\mathrm{gC1qR} / \mathrm{p} 33$ : a novel mechanism for staphylococcal interactions with platelets. Infect. Imm. 68, 2061-2068 (2000).

151. Gómez MI, Lee A, Reddy B et al. Staphylococcus aureus protein A induces airway epithelial inflammatory responses by activating TNFR1. Nat. Med. 10, 842-848 (2004).

152. Gómez MI, Seaghdha MO, Prince AS. Staphylococcus aureus protein A activates TACE through EGFR-dependent signaling. EMBO J. 26, 701-709 (2007).

153. Martin FJ, Gomez MI, Wetzel DM et al. Staphylococcus aureus activates type I IFN signaling in mice and humans through the $\mathrm{Xr}$ repeated sequences of protein A. J. Clin. Invest. 119, 1931-1939 (2009).
154. Merino N, Toledo-Arana A, Vergara-Irigaray $\mathrm{M}$ et al. Protein A-mediated multicellular behavior in Staphylococcus aureus. J. Bacteriol. 191, 832-843 (2009).

155. Siboo IR, Chambers HF, Sullam PM. Role of SraP, a serine-rich surface protein of Staphylococcus aureus, in binding to human platelets. Infect. Imm. 73, 2273-2280 (2005).

156. Loughman A, Fitzgerald JR, Brennan MP et al. Roles for fibrinogen, immunoglobulin and complement in platelet activation promoted by Staphylococcus aureus clumping factor A. Mol. Microbiol. 57, 804-818 (2005).

157. Hair PS, Echague CG, Sholl AM et al. Clumping factor $\mathrm{A}$ interaction with complement factor I increases C3b cleavage on the bacterial surface of Staphylococcus aureus and decreases complement-mediated phagocytosis. Infect. Imm. 78, 1717-1727 (2010).

158. Higgins J, Loughman A, van Kessel KP et al. Clumping factor A of Staphylococcus aureus inhibits phagocytosis by human polymorphonuclear leucocytes. FEMS Microbiol. Lett. 258, 290-296 (2006).

159. Josefsson E, Hartford O, O'Brien L et al. Protection against experimental Staphylococcus aureus arthritis by vaccination with clumping factor $A$, a novel virulence determinant. J. Infect. Dis. 184, 1572-1580 (2001).

160. Vernachio J, Bayer AS, Le T et al. Anticlumping factor $\mathrm{A}$ immunoglobulin reduces the duration of methicillin-resistant Staphylococcus aureus bacteremia in an experimental model of infective endocarditis. Antimicrob. Agents Chemother. 47, 34003406 (2003).

161. Entenza JM, Moreillon P, Senn MM et al. Role of $\sigma \mathrm{B}$ in the expression of Staphylococcus aureus cell wall adhesins ClfA and FnbA and contribution to infectivity in a rat model of experimental endocarditis. Infect. Imm. 73, 990-998 (2005).

162. Miajlovic H, Loughman A, Brennan Met al. Both complement- and fibrinogen-dependent mechanisms contribute to platelet aggregation mediated by Staphylococcus aureus clumping factor B. Infect. Imm. 75 , 3335-3343 (2007).

163. O'Brien LM, Walsh EJ, Massey RC et al. Staphylococcus aureus clumping factor B (ClfB) promotes adherence to human type I cytokeratin 10: implications for nasal colonization. Cell. Microbiol. 4, 759-770 (2002).

164. Haim M, Trost A, Maier CJ et al. Cytokeratin 8 interacts with clumping factor B: a new possible virulence factor target. Microbiology 156, 3710-3721 (2010). 
165. Corrigan RM, Miajlovic H, Foster TJ. Surface proteins that promote adherence of Staphylococcus aureus to human desquamated nasal epithelial cells. BMC Microbiol. 9, 22-32 (2009).

166. Walsh EJ, O'Brien LM, Liang X et al. Clumping factor $\mathrm{B}$, a fibrinogen-binding MSCRAMM (microbial surface components recognizing adhesive matrix molecules) adhesin of Staphylococcus aureus, also binds to the tail region of type I cytokeratin 10 . J. Biol. Chem. 279, 50691-50699 (2004).

167. Barbu EM, Ganesh VK, Gurusiddappa S et al. $\beta$-Neurexin is a ligand for the Staphylococcus aureus MSCRAMM SdrC. PLoS Pathog. 6, e1000726 (2010).

168. Sabat A, Melles DC, Martirosian G, Grundmann $\mathrm{H}$ et al. Distribution of the serine-aspartate repeat protein-encoding $s d r$ genes among nasal-carriage and invasive Staphylococcus aureus strains. J. Clin. Microbiol. 44, 1135-1138 (2006).

169. Sitkiewicz I, Babiak I, Hryniewicz W. Characterization of transcription within $s d r$ region of Staphylococcus aureus. Antonie Van Leeuwenhoek 99, 409-416 (2011).

170. O’Brien L, Kerrigan SW, Kaw G et al. Multiple mechanisms for the activation of human platelet aggregation by Staphylococcus aureus: roles for the clumping factors ClfA and $\mathrm{ClfB}$, the serine-aspartate repeat protein SdrE and protein A. Mol. Microbiol. 44, 1033-1044 (2002).

171. Tristan A, Ying L, Bes M et al. Use of multiplex PCR to identify Staphylococcus aureus adhesins involved in human hematogenous infections. J. Clin. Microbiol. 41, 4465-4467 (2003).
172. Persson L, Johansson C, Rydén C. Antibodies to Staphylococcus aureus bone sialoproteinbinding protein indicate infectious osteomyelitis. Clin. Vaccine Immunol. 16, 949-952 (2009).

173. Vazquez V, Liang X, Horndahl JK et al. Fibrinogen is a ligand for the $S$. aureus MSCRAMM Bbp (Bone sialoprotein-binding protein. J. Biol. Chem. 286(34), 2979729805 (2011).

\section{Website}

101. National joint registry www.njrcentre.org.uk 